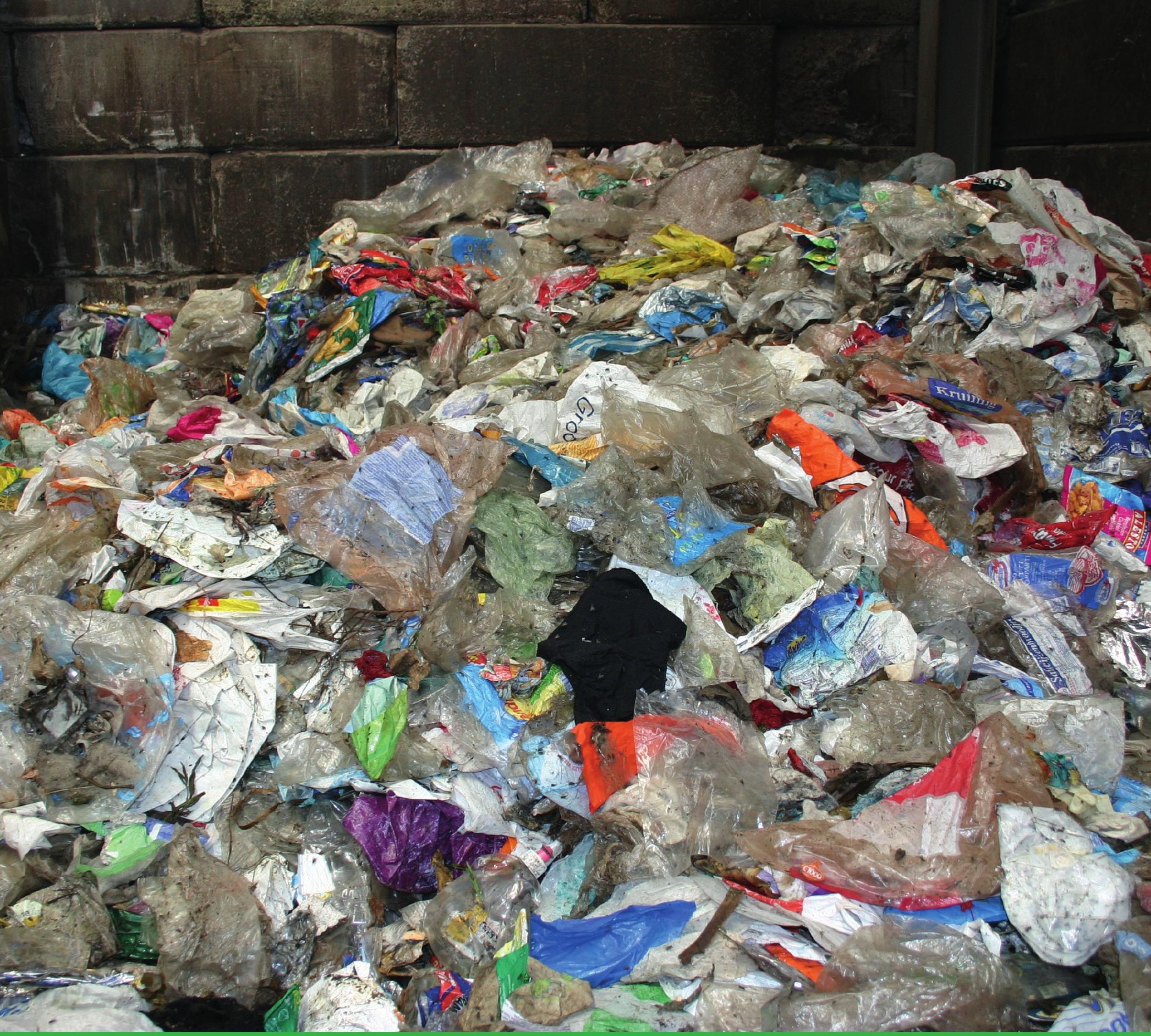

\title{
Flexible laminates within the circular economy
}





\section{Flexible laminates within the circular economy}

Authors: Ulphard Thoden van Velzen, Lisanne de Weert, Karin Molenveld

This research project was conducted through the Center for Research in Sustainable Packaging (CriSP). This report is prepared by Wageningen Food \& Biobased Research and sponsored by the Netherlands institute for sustainable packaging (KIDV) and the Dutch Ministry of Agriculture Nature and Food Quality, (project number 62290809). 
Version: final

Reviewer: Fresia Alvarado Chacon

Approved by: Arie van der Bent and Christiaan Bolck

Client: CRiSP

Sponsor: KIDV and the Dutch Ministry of Agriculture Nature and Food Quality

This report can be downloaded for free at https://doi.org/10.18174/519019 or at www.wur.eu/wfbr (under publications).

(C) 2020 Wageningen Food \& Biobased Research, institute within the legal entity Stichting Wageningen Research.

The client is entitled to disclose this report in full and make it available to third parties for review according to consortium agreement OPD 18/039/20180516. Without prior written consent from Wageningen Food \& Biobased Research, it is not permitted to:

a. partially publish this report created by Wageningen Food \& Biobased Research or partially disclose it in any other way;

b. (let a third party) use this report created by Wageningen Food \& Biobased Research or the name of the report or Wageningen Food \& Biobased Research in whole or in part for the purposes of making claims, conducting legal procedures, for (negative) publicity, and for recruitment in a more general sense;

c. use the name of Wageningen Food \& Biobased Research in a different sense than as the author of this report.

PO box 17, 6700 AA Wageningen, The Netherlands, T + 31 (0)317 4800 84, E info.wfbr@wur.nl, www.wur.eu/wfbr. Wageningen Food \& Biobased Research is part of Wageningen University \& Research.

All rights reserved. No part of this publication may be reproduced, stored in a retrieval system of any nature, or transmitted, in any form or by any means, electronic, mechanical, photocopying, recording or otherwise, without the prior permission of the publisher. The publisher does not accept any liability for inaccuracies in this report. 


\section{Contents}

$\begin{array}{lr}\text { Summary } & 5\end{array}$

$1 \quad$ Introduction and motive $\quad 6$

1.1 Objective and outline $\quad 6$

$\begin{array}{lll}1.2 & \text { Circularity goals \& the new plastics economy } & 6\end{array}$

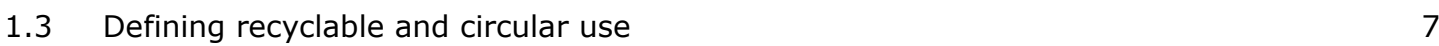

$\begin{array}{llr}1.4 & \text { Laminates and recycling } & 8\end{array}$

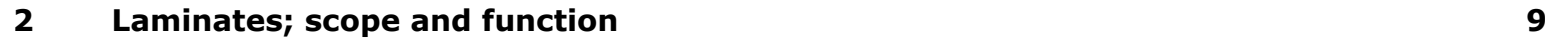

2.1 Definition of laminates and scope chosen in this report 9

2.1.1 Definition and scope $\quad 9$

2.1.2 Packaging type 9

2.1.3 Laminate film production $\quad 9$

2.2 The function of laminates from a packaging perspective 10

2.2.1 Transportation characteristics 10

2.2.2 Communication and marketing 10

2.2.3 Protective function of the laminates 10

2.2.3.1 Mechanical properties and requirements 10

2.2.3.2 Physical properties and requirements 10

2.2.3.3 Biological requirements 11

2.2.3.4 Additional remarks $\quad 11$

$\begin{array}{lll}2.3 & \text { Environmental benefits of laminates } & 11\end{array}$

2.3.1 Food waste 11

2.3.2 Material reduction $\quad 12$

$3 \quad$ Current laminates $\quad 13$

$\begin{array}{llr}3.1 & \text { Introduction } & 13\end{array}$

3.2 The individual layers within laminates 13

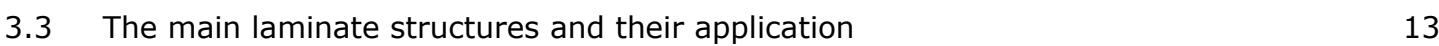

3.3.1 Introduction $\quad 13$

3.3.2 Metallised BOPP(/PE) laminates $\quad 14$

3.3.3 Metallised BOPET/PE laminates and massive Aluminium laminates $\quad 14$

3.3.4 PA/PE laminates 14

3.3.5 PET/PE and PE/PP laminates $\quad 15$

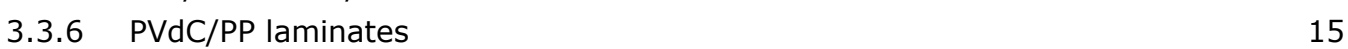

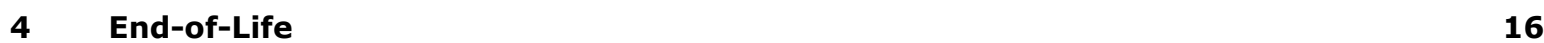

$\begin{array}{lll}4.1 & \text { Introduction } & 16\end{array}$

4.2 Current situation of waste management 16

$\begin{array}{ll}4.3 \text { Mechanical recycling } & 17\end{array}$

$\begin{array}{ll}\text { 4.3.1 Introduction } & 17\end{array}$

$\begin{array}{ll}\text { 4.3.2 Technical aspects } & 17\end{array}$

$\begin{array}{ll}4.4 & \text { Chemical and thermal recycling } \\ \end{array}$

4.4.1 Introduction $\quad 19$

4.4.2 Technical aspects 19

4.4.2.1 Chemical methods; Solvolysis 19

4.4.2.2 Chemical methods; Selective dissolution 19

4.4.2.3 Thermal methods; pyrolysis and gasification $\quad 19$

$\begin{array}{lll}4.5 & \text { Organic recycling } & 20\end{array}$

$\begin{array}{ll}\text { 4.5.1 Introduction } & 20\end{array}$

$\begin{array}{lll}4.5 .2 & \text { Technical aspects } & 20\end{array}$ 
4.5.3 Practical and economical limitations and acceptance 21

$\begin{array}{ll}4.6 & \text { Paper recycling } \\ \end{array}$

$\begin{array}{llr}5 & \text { Stakeholders } & 23\end{array}$

$\begin{array}{llr}5.1 & \text { Introduction } & 23\end{array}$

5.2 Position of the government $\quad 23$

$\begin{array}{lll}5.3 & \text { Position of the plastic producers and converters } & 23\end{array}$

$\begin{array}{lll}5.4 & \text { Position of food producing companies and retail } & 24\end{array}$

$\begin{array}{ll}5.5 & \text { Position of civilians } \\ 5.6 & 25\end{array}$

5.6 Position of waste management, sorting and recycling industries 25

$\begin{array}{lll}5.7 & \text { Industrial challenges with respect to laminates } & 26\end{array}$

6 Discussion; improving end-of-life options of flexible laminates 27

$\begin{array}{lll}6.1 & \text { Introduction } & 27\end{array}$

$\begin{array}{lll}6.2 & \text { Strategies } & 27\end{array}$

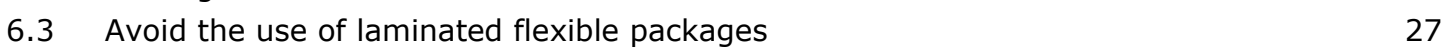

$\begin{array}{lll}\text { 6.3.1 General approach } & 27\end{array}$

6.3.2 Additional comments on this strategy 28

6.4 Redesign the laminates to new flexible packages that fit in one of the existing recycling $\begin{array}{ll}\text { schemes } & 28\end{array}$

6.4.1 General approach 28

6.4.2 Additional comments on the development of mechanically recyclable laminated flexible packages $\quad 28$

6.4.2.1 Laminated films that can be recycled with PE films 28

6.4.2.2 The use of water soluble tie-layer/barrier materials $\quad 29$

6.4.3 Additional comments on laminates in organic or paper recycling 29

6.4.3.1 Compostable laminates $\quad 29$

6.4.3.2 Paper recyclable laminates $\quad 30$

6.5 Change the collection, sorting \& recycling processes to fit in existing or novel laminated flexible packages $\quad 30$

6.5.1 General approach 30

6.5.2 Additional comments on these strategies $\quad 30$

6.5.2.1 Mono collection of specific laminates $\quad 30$

6.5.2.2 Create a separate sorted product for aluminium containing laminates $\quad 30$

6.5.2.3 Create a sorted product for paper laminates 30

6.5.2.4 Create a new sorted product for organic recyclable packaging 31

6.5.2.5 Separate the laminate layers and recycle them separately 31

6.5.2.6 Improve the properties of laminates using compatibilisers 31

6.5.2.7 Chemical recycling 31

6.5.2.8 Thermal recycling $\quad 31$

6.6 Make unavoidable non-recyclable laminate better recognisable and sortable $\quad 32$

6.6.1 Comments on this strategy $\quad 32$

$\begin{array}{llr}6.7 & \text { General recommendations } & 32\end{array}$

7 Conclusions 


\section{Summary}

This report focusses on flexible laminated packages that are composed out of multiple polymer types and their impact on the recycling chains. Approximately 3-4\% of the packaging products used in Europe is a laminated flexible packaging film. By nature, these films are either more difficult to recycle than mono-material packaging products, or even impossible to recycle.

In the Netherlands roughly $65 \%$ of the laminated flexibles are discarded with the mixed municipal solid waste and $35 \%$ are collected in separate collection schemes for lightweight packaging wastes. After sorting the laminates are distributed over the various sorted products; roughly $60 \%$ ends up in the sorted product MIX, 25\% in the sorted product FILM, 10\% in the various sorting residues and $5 \%$ in valuable sorting products like PP and PE where they may hinder recycling of these valuable sorting products.

Current and future options for the waste management of multi-material laminated flexible packaging films include mechanical-, chemical- and organic recycling. Next to technical feasibility and technical hurdles there are various practical and economical limitations and acceptance issues that presently limit recycling of flexible laminates.

Most stakeholders involved in plastic packaging are committed to develop a more sustainable, circular plastics industry. Despite the willingness of industry to move to sustainable and recyclable packaging products there are numerous challenges with respect to flexible laminates for packaging applications.

Strategies to improve the end-of-life options for flexible laminates can be categorised in four main categories; avoid the use of laminates, redesign the laminates, redesign the collection \& recycling scheme or improve the sort-ability and recognisability.

As a first step (agreement on) a precise definition of recyclability is needed to allow evaluation of the recyclability of laminated flexible packages. This implies that a test method is needed to verify if newly developed laminated flexibles are recyclable 


\section{$1 \quad$ Introduction and motive}

\section{$1.1 \quad$ Objective and outline}

The objective of this report is to initiate research and developments that will stimulate recycling and circular use of flexible laminates. For this purpose, an overview is presented of the current use of laminated flexible packaging films in the Netherlands. Also, the fate of these laminates in the current waste management system is estimated and issues that are experienced with these laminates in recycling are discussed. The report concludes with recommendations how laminated flexible packaging can better fit in a circular economy.

This research was conducted independently by the Center for Research in Sustainable Packaging (CRiSP), a consortium of the University of Twente, Utrecht University, Wageningen Food \& Biobased Research and the Netherlands Institute for Sustainable Packaging (KIDV), that develops and disseminates knowledge on sustainable packaging for industry and society (Consortium agreement; OPD 18/039/20180516). This position paper is prepared to initiate one of the first projects within CRiSP that focusses on improving the recyclability and circularity of flexible laminates. The paper is prepared by Wageningen Food \& Biobased Research and sponsored by KIDV and the Dutch Ministry of Agriculture Nature and Food Quality.

\subsection{Circularity goals \& the new plastics economy}

Despite their excellent technical performance, plastics are generally associated with environmental issues that may vary from greenhouse gas emissions, climate change, littering, "the plastic soup" to micro plastics. The negative perception is strongly directed towards packaging and other "single use" plastic products that significantly contribute to waste generation. A focus on plastic packaging is valid since about $40 \%$ of all plastics produced are used in packaging products that typically have a short life time. Installing closed waste management systems is an excellent manner to reduce littering issues (but cannot completely prevent littering) and at the same time reduce greenhouse gas emissions. This is excellently depicted in the "New plastics economy" view presented by the Ellen MacArthur Foundation.

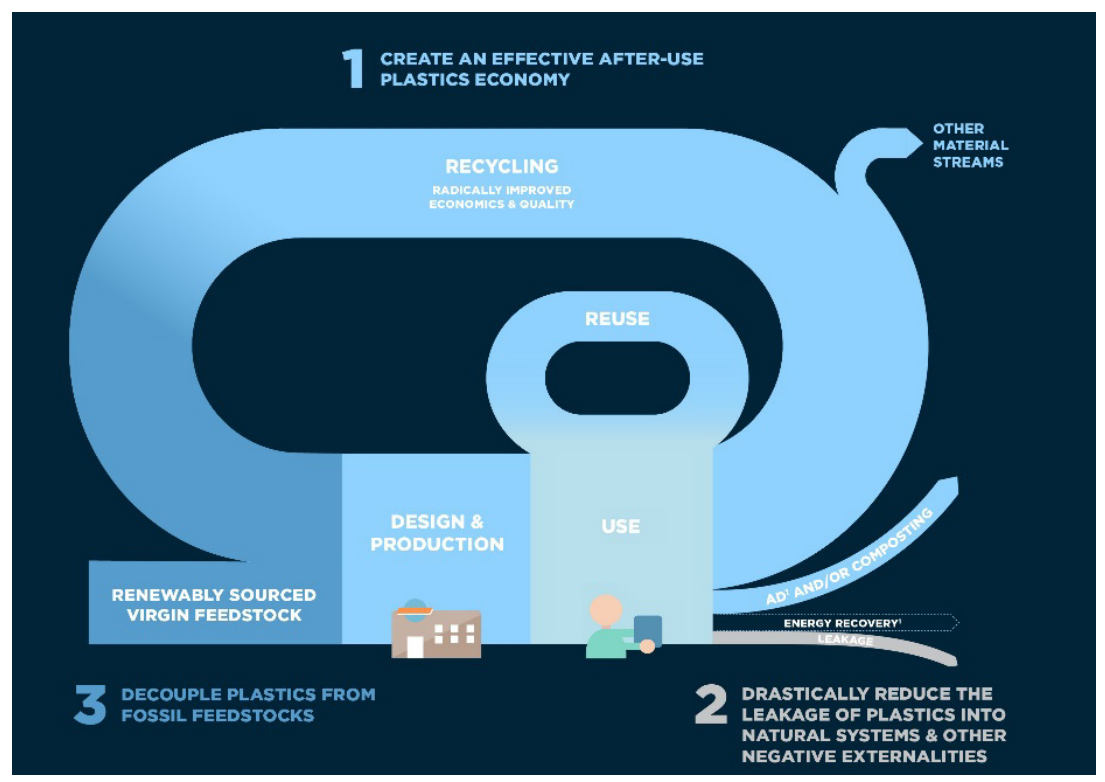

Figure 1 The "New Plastics Economy" (Ellen MacArthur Foundation)[1] 
The 3 key elements of the "New Plastics Economy" are:

1. Creating an effective after-use plastics economy

2. Drastically reduce the leakage of plastics in to natural systems

3. Decouple plastics from fossil feed stocks.

Elements of the "New Plastics Economy" are clearly found in the European Plastics Strategy that was released by the European Commission on January $16^{\text {th }}, 2018$. The European Plastics Strategy contains over 50 actions. A key element with respect to plastic packaging is the target that all plastics packaging in the EU needs to be recyclable by 2030 [2]. The Dutch government supports these European recycling targets and aims to reach these by cooperating with industries [3]. As a response to the recycling targets various multinationals including Unilever, Coca-Cola and Nestlé have announced that they want all their plastic packaging to be reusable, recyclable or compostable by 2025. This is even more ambitious then the target set by the EU.

"The New Plastics Economy Global Commitment", led by the Ellen MacArthur Foundation, is signed by 250 organisations including packaging producers, brands, retailers and recyclers, as well as governments and NGOs [4]. Signatories include companies representing $20 \%$ of all plastic packaging produced globally. They include well-known consumer businesses such as Danone, H\&M group, L'Oréal, Mars Incorporated, PepsiCo, The Coca-Cola Company and Unilever, major packaging producers such as Amcor, plastics producers including Novamont, and resource management company Veolia. The Global Commitment aims to create 'a new normal' for plastic packaging. Targets (that will be reviewed and become more demanding every 18 months) include:

- Eliminate problematic or unnecessary plastic packaging and move from single-use to reuse packaging models.

- Innovate to ensure $100 \%$ of plastic packaging can be easily and safely reused, recycled, or composted by 2025.

- Circulate the plastic produced, by significantly increasing the amounts of plastics reused or recycled and made into new packaging or products.

On February $21^{\text {st }} 2019$ in total 75 Dutch companies and organisations as well as the Ministry of Infrastructure and Water Management have entered into a new "Plastic Pact" under which they commit to use less and recycle more plastic [5]. Within the plastic pact the signatories commit to four goals which need to be achieved by 2025.

- All plastic products and packaging will be made out $100 \%$ recyclable plastic.

- $\quad 20 \%$ less plastic will be used in 2025 as compared to 2017.

- At least $70 \%$ of the single-use plastic products and packages in the Netherlands will undergo high quality recycling,

- All plastic single-use items placed on the market will have a recycled content of at least $35 \%$.

The implication of the various circularity goals for each individual company will vary depending on their specific packaging and product portfolio. An important topic that still needs to receive attention is the definition of the term 'recyclable' and the development of criteria to measure recyclability. Not only with respect to the quality of recycled plastics but also to the type of waste management system or even the presence of a waste management system. This has led to the introduction of terms like "recycle ready" to replace "recyclable".

\subsection{Defining recyclable and circular use}

Plastic recycling is the process in which recovered plastic scrap or other plastic waste is reprocessed into useful products or materials. These recycling products can vary depending on the precise recycling process: monomers, washed milled goods, granulates, compounds, agglomerates and new products (packages, chairs, waste bins). To determine whether a plastic (packaging) product is recyclable the PRE (Plastic Recyclers Europe) proposes the following four criteria [6]: 
1. The product must be made with a plastic that is collected for recycling, has a market value and/or is supported by a legislatively mandated program.

2. The product must be sorted and aggregated into defined streams for recycling processes.

3. The product can be processed and reclaimed/recycled with commercial recycling processes.

4. The recycled plastic becomes a raw material that is used in the production of new products.

With respect to new materials they state that innovative materials must demonstrate that they can be collected and sorted in sufficient quantities, must be compatible with existing industrial recycling processes or will have to be available in sufficient quantities to justify operating new recycling processes. Although these four criteria of recyclability are helpful, they are often insufficient discriminating to assess the recyclability of laminated flexible packages.

Circular use of plastic packaging suggests that plastic packaging waste is reprocessed into new packaging materials. Still there is no precise definition of circularity and according to literature Circular Economy means different things to different people $[7,8]$. Often closing the loop for material and energy is a part of the definition, but also maintaining the value of products and waste minimisation is frequently mentioned. Linder discusses circularity on a product level and describes a set of principles for measuring product circularity [9]. He defines circularity at a product level as "the fraction of a product that comes from used products" (both from closed- or open-loop cycles).

A clear example of circular recycling is the recycling of PET bottles into PET bottles. However, the recycling of PET bottles into strapping and fleece fill is not always considered as 'circular' by everybody.

Often a practical interpretation of the terms recyclable and circular regarding plastic packages is that recyclable plastic package can be recycled into the following recycled products: PET, PE, PP, Film and MIX, whereas circular plastic packages can be recycled into PET, PE, PP and Film. Hence, the recycling into MIX is not considered circular recycling and may not comply with recycling criteria set by the PRE because of the low market value. Moreover, if the quality of the recycled Film product is insufficient for reprocessing into films, it will also not be considered a circular form of recycling.

\subsection{Laminates and recycling}

This report focusses on flexible laminated packages that are composed out of multiple polymer types and their impact on the recycling chains. These laminated flexible packages enable the distribution of multiple food products, giving these food products maximum protection and shelf life at minimum packaging weights, and are hence vital for our economies. However, the multi-material nature of these laminates make them difficult to recycle and hence they are not easily accommodated within circular economy concepts. Often, these laminated flexible packages are classified as non-recyclable packages [10]. Moreover, these laminated flexible packages cause polymeric contamination in all the traditional recycled plastic products. Although a relative small packaging category, they have a relatively large impact in lowering the quality of most recycled plastics and thereby form one of the most challenging packaging categories in achieving a more circular economy.

Typically, flexible laminates are combinations of different plastic types that have their own specific function in the film or packaging product like for example sealing ability, strength, stiffness, or oxygen barrier. Since in general different polymer types are immiscible, mechanical recycling of laminates (and mixing the various components) will result in products with poor optical and mechanical properties. Moreover, various components of the laminate can be disturbing or even detrimental during the recycling process itself like the presence of polyvinylidene chloride (PVdC) or aluminium [11]. Although there is scientific knowledge on the compatibilisation of immiscible polymer blends there is little scientific information on the recyclability of laminates [12-16]. Moreover, an integrated analysis of the recycling of laminates should also encompass the current and future waste management systems that include disposal by civilians, collection systems, sorting processes and recycling processes (mechanical, chemical, organic, thermal). All these factors influencing the recycling and recyclability of laminates will be addressed in chapter 4 . 


\section{Laminates; scope and function}

\subsection{Definition of laminates and scope chosen in this report}

\subsubsection{Definition and scope}

The word laminate in this report refers to multi-material multi-layer, flexible packaging films. The overall composition of the laminate is leading, not the specific structure nor the production method.

\subsubsection{Packaging type}

Laminates are predominantly applied in primary packaging. The scope in this report is thus limited to primary packaging of (food) products. A primary package is the package that is in direct contact with the product, is presented on the shelves and is taken home by the consumer. The most important functions of this package are chemical, biological and to a lesser extend mechanical protection. Moreover, the package sells the product to the consumer and is a platform for communicating product information to the consumer [17]. In further use, the term 'packaging' will refer to the primary packaging of a (food) product.

A further limitation of the scope in this report is the focus on flexible packaging and typically multimaterial films. This implies that rigid laminate products (most commonly thermoformed products) are excluded. Typical packaging products based on laminate films within the scope of this report are bags, wrappers, flow-packs, top-lidding film and (stand-up) pouches that are used to pack product ranging from chips and bakery products to cheese, meat, soup and coffee.

\subsubsection{Laminate film production}

Multi-layer films can be produced in different ways, depending on the used materials, production batch, composition and film requirements. Two different production methods can be applied; coextrusion and lamination. Using co-extrusion, a plastic film containing two or more distinct plastic layers can be produced without requiring any intermediate steps. Lamination refers to a process in which two or more plastic films are produced first, and then adhered together.

Co-extrusion can be used to produce both cast and blown multi-layer films. A machine layout is required with multiple extruders that simultaneously extrude and produce a film composed of different polymer layers. The separate polymer layers can be extremely thin, and the number of layers commonly ranges from 5 to 13 . The production method is suitable for polymer materials that have similar melting behaviour and viscosity and is often used for large series of PE-PP, PE-EVOH-PP and PA-EVOH-PE laminates. Often additional tie-layers are used [18].

Lamination is a technique used for materials with incompatible production methods, such as paper, aluminium and cellophane, but also for films that need biaxial orientation to obtain the required properties (like PET and PP). Lamination methods include extrusion lamination, adhesive lamination, wax and hot melt lamination and coating techniques.

Well-known products produced via extrusion lamination are structures based on PE and paper(board). Adhesive lamination is commonly used to produce plastic-film-based structures (e.g. PE-PET), including laminates with aluminium.

Coating provides a thin layer of material on a base material. This layer can add functionality such as improved sealing, barrier or protective properties. Examples of coating materials are PVdC, polyacrylates and nitrocellulose. Vapour deposition is a suitable method for the application of a very thin layer (nanometre range) of inorganic materials e.g. aluminium, $\mathrm{AlO}_{\mathrm{x}}$ or $\mathrm{SiO}_{\mathrm{x}}$ on another material $[17,19]$. 
Though different production methods will lead to different compositions and constructions of the laminate, this is less relevant for the ability to recycle a laminate. If the layers of the laminate are inseparable it will be the composition that determines their behaviour during recycling rather than the production method. Focus will therefore be on the overall composition of the flexible packaging structure.

\subsection{The function of laminates from a packaging perspective}

\subsubsection{Transportation characteristics}

The primary role of secondary and tertiary packages is enable the transportation without causing mechanical damage. Nevertheless, also the primary package should enable transportation and handling of the product. Laminates have the benefit of providing good protective properties at low weight and volume. These characteristics benefit transportation by facilitating handling. They also reduce energy consumption and optimize required space for transportation.

\subsubsection{Communication and marketing}

Persuasive designs convincing the consumer to purchase the product is just a small part of the communicational function of a package. Type of product, content quantity, nutritional value, ingredients and brand are all relevant to depict. Correctly chosen (top layers of) laminates can provide a large benefit in design and communication, as the entire surface can be full-colour printable [17, $18]$.

\subsubsection{Protective function of the laminates}

The protection of the contained product, and thus avoidance of food waste, is a large environmental benefit of packaging. The food product should be protected from mechanical, physical, biological and chemical influences.

\subsubsection{Mechanical properties and requirements}

Shape-rigidity, the ability to retain an intended shape despite forces acting upon the package, is determined by the contained product and mechanical properties such as elasticity and tensile strength of the packaging. Layered structures containing a LDPE core and HDPE outer layers can provide increased stiffness compared to mixed or two-layer LDPE-HDPE laminates [20]. Alternatively more rigid film layers like Aluminium or PET can be used in combination with a flexible material like LDPE [21]. Puncture resistance is required to withstand perforation of the package by impact or sharp objects and it is improved with the toughness (as opposed to brittleness) of the material. The package should not be damaged when a packed food product is dropped. This is determined by the elasticity and structure of the package (e.g. use of buffer-zones). For flexible laminate packaging, the secondary or tertiary packaging are the main contributors to stack resistance, a property required for optimum stacking [17].

\subsubsection{Physical properties and requirements}

Visible light, UV-radiation and X-rays can deteriorate the quality of various food products such as beer, cured meats and dairy products. The primary package can protect the food products by absorbing the harmful radiations. Water vapour can deteriorate food texture and oxygen speeds up the oxidative degradation of foods. Depending on which quality decay mechanism is leading for a food product, either moisture ingress and/or oxygen ingress has to be reduced $[17,18]$. Where metals and glass block the diffusion of nearly all substances entirely, the permeability of molecules through polymers differs per substance and material. The polarity of the material and free volume between polymer chains, in combination with the (kinetic) diameter of permeating molecules determines the diffusion rate $[22,23]$. As oxygen, carbon dioxide and water molecules are smaller than e.g. aroma molecules, 
the latter will usually permeate slower through a material [24]. A nonpolar, or hydrophobic material (such as PE) will provide an efficient barrier to water vapour. In contrast polar materials such as starch and PVOH possess elevated water vapour transmission rates. For small gases such as oxygen and carbon dioxide the opposite is true; these gases permeate in small amounts through polar polymers at low levels of humidity and much larger amounts through nonpolar polymers. High density materials (such as HDPE) will provide a better barrier compared to low density materials (such as LDPE) due to smaller free volumes [22].

Laminates provide the ability to combine different materials with different barrier properties and thus prolong shelf life. Aluminium layers in laminates provide an excellent barrier to (UV) light, water vapour, oxygen gas, carbon dioxide gas, aroma molecules and thermal fluctuations and are thus often applied in laminates. $\mathrm{EVOH}, \mathrm{PVdC}, \mathrm{AlO}_{x}$ and $\mathrm{SiO}_{x}$ layers also provide excellent gas barriers, but all have their own set of drawbacks. EVOH is relative sensitive to moisture and the effective gas barrier is moisture dependent. PVdC degrades recycling products and the application of the AlOx and SiOx in flexible packaging need specific precautionary measures during production and use to prevent stresscracking of the brittle film [25].

In barrier packaging apart from the film itself there are specific requirements on the sealing quality. $\mathrm{PE}$ and CPP offer the best sealing quality and the latter is suitable in packaging that needs to be sterilized.

\subsubsection{Biological requirements}

Besides degradation of the product, the presence of oxygen can facilitate the growth of aerobic microorganisms. A well-known packaging technique to maintain the quality of food products is modified atmosphere packaging, in which the quality loss of the food products is retarded by packaging it in a modified atmosphere, which is either low in oxygen, or low in oxygen and high in carbon dioxide. In both cases, the package needs to maintain the protective atmosphere of the headspace, which is often achieved by applying gas-barrier films, which are in almost all cases laminated flexible films.

Sterilisation can provide total inactivation of microorganisms before opening the package. Still, only few polymeric materials are suitable for sterilization. After sterilisation the food products in principle have long shelf lives if they are protected from moisture, oxygen and sometimes also light. Laminated flexible packages can offer those functions.

Moreover, pinholes, cracks or defects in the seal can enable insects, bacteria and fungi to enter the package. Laminates often contain a smooth surface and a well- sealed inner layer to prevent this [17].

\subsubsection{Additional remarks}

Where the choice of material (combinations) determines the abovementioned properties to a large extent, the crystallinity (alignment of polymer-molecules) and orientation of a material also influence the stiffness, strength, density and permeability. A well-known example is BOPP film (Biaxially Oriented PP) film with an improved strength and clarity as compared to non-oriented PP.

\subsection{Environmental benefits of laminates}

\subsubsection{Food waste}

As described in the previous section, packaging protects the contained product which increases the shelf life of products and reduces food waste. Especially laminates provide excellent barriers to microorganisms, light, oxygen gas, carbon dioxide gas and water vapour, which are most prone to degrade the product $[26,27]$. The environmental impact of food (production, processing, storage, ..) can be between 5 (for vegetables and fruits) and 190 (for meat) times higher compared to their package. The environmental impact of a package should therefore be regarded in combination with the contained product $[28,29]$. An increase in shelf life, can decrease food waste in retail, which is especially true for fresh products with relatively short shelf lives [30-32]. 
Although the contribution of laminated flexible packages to the shelf life of food products remains unchallenged, the relation with food waste strongly varies with packaging type and packed product $[33,34]$. For food waste in supermarkets, there is a clear relation with the shelf life and the order policy and in general a longer shelf life reduce the food waste in supermarkets [31]. Regarding food waste at households, this type of food waste is a consequence of human behaviour and hence civilians can also get accustomed to long shelf lives, alter their purchase and consumption behaviour and therefore still cause food waste for food products with a long shelf life. Confusion and misunderstanding on how the "best-before date" on a package relates to food safety and quality significantly adds to food spoilage [33]. Furthermore also other factors such as portion size play an important role in the food spoilage at households [35].

\subsubsection{Material reduction}

The introduction of laminates in the 1970's resulted in a revolution in packaging design. It gave packaging developers the ability to drastically reduce the amount of used packaging material per unit of product, and consequently significantly reduce the environmental impact $[26,36]$.

Sustainability awards went out to manufacturers changing from heavy mono-material pots, jars and cans to flow packs and stand-up pouches of plastic laminates [37]. A second increase in use of laminates was initiated by the development of said 'stand-up pouches', which found wide application due to low costs, high possible line speed, durability and attractive shelf presence [27, 38, 39]. Also, a marketing-benefit is the avoidance of aluminium, which is sometimes perceived as environmentally unfriendly by consumers $[40,41]$. Again, material reduction leading to environmental benefits was considered an important benefit of this new packaging concept. The combination of materials in the pouch provides required barriers and stiffness to remain in upright position at low weight [27]. When comparing the environmental impact (through life cycle analysis) of e.g. steel cans, HDPE canisters and coated paperboard (which are all partially recycled), to the impact of a non-recyclable laminate package with comparable functionality, the impact of the latter is still between 3 and 8 times lower [42]. 


\section{Current laminates}

\subsection{Introduction}

An amount of 0.6 million tonne of multi-layered laminated flexible packaging is estimated to enter the European market each year [26] whereas the total demand for plastic packaging in Europe is estimated just over 20 million tonnes [43]. This implies that about 3\% of the packaging products used in Europe is a laminated flexible packaging film. This data is in line with figures from the CEFLEX project ( 0.75 million tonnes multilayer laminated flexible film) and with Dutch material flow analysis studies of packaging materials that found 15 kton multilayer laminated flexible packages for households on a total of 350 kton of post-consumer plastic packaging materials (hence $4 \%$ ), see chapter 4. All figures are highly similar, and differences can be explained by the diverse definitions of flexible laminates. In this chapter, the separate laminate layers and their functions are described, as well as the main laminate groups used in primary (food) packaging. Knowledge on the structures and functions is helpful to estimate effects on recycling as well as understanding the potential impact of changes in laminate structure to facilitate recycling.

\subsection{The individual layers within laminates}

The various types of food products are prone to different quality decay pathways which can be retarded by a well-designed package. This implies that various food products require the package to possess different types of barrier properties, for moisture, gas and / or light. As it is impossible to find a single material that meets all requirements at low costs and low weight, material combinations are used. Each material in the laminate serves a distinct purpose. Dividing the functions of a laminate into categories will give insight into the assembly of laminates (see Table 1 on the next page).

Each product type and packaging design entails different material requirements. Not every laminate is composed of the same materials and different assemblies of the same materials can have different benefits in specific applications, as described in Table 1.

\subsection{The main laminate structures and their application}

\subsubsection{Introduction}

Typical examples of laminate structures are:

- $\quad$ PE-PA-PE with tie layers to protect against moisture and gas

- $\quad$ Print-PET-AI-PE to protect against moisture, gas and light.

- $\quad$ PP-PA-CPP sterilisable bags to protect against moisture and gas

Laminate structures depend on the type of protection needed to preserve a specific product and the type of package (lidding film, wrap, bag, pouch). This has led to the development of numerous laminate structures. Still, the laminates can be categorised in main groups based on the type of materials used in the laminate (in this report the laminate composition is leading). 
Table 1 Typical functions of laminate layers [12, 18-20].

\begin{tabular}{|c|c|c|c|c|}
\hline Layer & Function & Goal & Material & Extra information \\
\hline Gas barrier & $\begin{array}{l}\text { Reduce diffusion of } \\
\text { gasses and aromas }\end{array}$ & $\begin{array}{l}\text { Increase shelf } \\
\text { life }\end{array}$ & $\begin{array}{l}\text { Al-foil, AlOx, SiOx, } \\
\text { EVOH, PVdC, Nylon, } \\
\text { PVOH }\end{array}$ & $\begin{array}{l}\text { Determined by the free volume } \\
\text { between the macromolecules, } \\
\text { polarity and size of permeating } \\
\text { molecules. Aromas are larger } \\
\text { molecules and migrate slower } \\
\text { than } \mathrm{O}_{2}, \mathrm{CO}_{2} \text { or } \mathrm{H}_{2} \mathrm{O} \text {. }\end{array}$ \\
\hline Moisture barrier & $\begin{array}{l}\text { Reduce water vapour } \\
\text { transmission rate }\end{array}$ & $\begin{array}{l}\text { Increase shelf } \\
\text { life }\end{array}$ & $\begin{array}{l}\text { HDPE, LDPE, OPP, } \\
\text { mOPP, Al-foil, AlOx, } \\
\text { SiOx, PVdC, }\end{array}$ & $\begin{array}{l}\text { Determined by solubility } \\
\text { coefficients of moisture in } \\
\text { polymers. }\end{array}$ \\
\hline Structural & Strength and stiffness & $\begin{array}{l}\text { Machinability, } \\
\text { appearance, } \\
\text { mechanical } \\
\text { resistance }\end{array}$ & $\begin{array}{l}\text { LDPE, HDPE, OPP, PET, } \\
\text { reinforced/filled } \\
\text { materials }\end{array}$ & $\begin{array}{l}\text { Layered structures with LDPE } \\
\text { centre and HDPE sides: I-beam } \\
\text { effect, balance stiffness and } \\
\text { toughness }\end{array}$ \\
\hline
\end{tabular}

\subsubsection{Metallised BOPP(/PE) laminates}

These are typically thin laminate films to pack products like crisps and bakery products. Main function of the package is the protection against moisture, oxygen and light. PE is often used for improved sealing. The optical density parameter of these metallised films is often used as indicator for the thickness of the aluminium layer and hence the oxygen gas permeability.

\subsubsection{Metallised BOPET/PE laminates and massive Aluminium laminates}

When high strength and stiffness are required in combination with good barrier properties (protection against UV and/or oxygen) metallised BOPET/PE laminates and BOPET/AI/PE laminates are frequently used. The laminates with metallised aluminium only have moderate gas barrier properties, while the laminates with $6 \mu \mathrm{m}$ thick massive aluminium layers have a near complete barrier for gases. The latter laminates are usually also stiffer, which is desirable in for example cat feed pouches. There is an increased use of $\mathrm{AlO}_{x}$ replacing thicker aluminium layers, but both are still widely applied in food packaging. This is partially due to better barrier function of laminates with massive aluminium layers and partially due to the less complicated handling on packaging machines. Product examples include packaging of coffee, stand-up pouches for soups and sauces but also pouches for cat food. In this laminate the PET layer provides strength and stiffness, the PE enables sealing and the aluminium layer provides barrier and depending on the thickness of the aluminium layer additional stiffness.

\subsubsection{PA/PE laminates}

PA/PE laminates have excellent puncture resistance and provide a barrier against water (PE) and oxygen (PA). These laminates are typically used to pack dried fruit, snacks and pre-baked bread and sometimes meat products. Also, these laminates are frequently used in vacuum bags for various packaging applications. 


\subsubsection{PET/PE and PE/PP laminates}

These laminates are used in products were the strength and/or stiffness of PE are not sufficient and when mediocre protection against gasses is sufficient. PE is primarily used as a sealing layer and can also provide a moisture barrier. Typically, PET/PE and PE/PP laminates are used to pack (dry) pasta and frozen foods.

\subsubsection{PVdC/PP laminates}

As an alternative to metallised films, laminates with PVdC are used to provide a gas (and water) barrier. Especially for food products that demand both a high gas barrier film and an optically transparent packaging film the PVdC based laminates are still in use. PVdC containing materials are most frequently used in meat packaging (lidding), cured-meat packaging and biscuit packaging. Since chlorine containing polymers are scrutinised for complicating the recycling of plastic packages, alternative barrier materials like $\mathrm{EVOH}$ and $\mathrm{PVOH}$ are also used in this application. 


\section{End-of-Life}

\subsection{Introduction}

This chapter summarizes the knowledge of the current and future options for the waste management of multi-material laminated flexible packaging films (mechanical-, chemical- and organic recycling) from various perspectives;

- The technical feasibility and technical hurdles

- Practical and economical limitations and acceptance (e.g. recognition and separate collection by consumers, costs of separation techniques and the economy of scale)

Technical and scientific information is combined with data from waste analysis performed by WFBR in recent years.

\subsection{Current situation of waste management}

A material flow analysis of post-consumer plastic packaging wastes in the Netherlands in 2017 revealed that roughly 15.2 kton of laminated flexibles are present on the Dutch market. Roughly 10.4 kton are discarded with the mixed MSW and are incinerated and roughly 4.8 kton are collected in separate collection schemes for lightweight packaging wastes [44, 45]. No reliable data is present on the amounts of laminates in organic waste, paper \& board waste, glass waste, etc. Furthermore, also no reliable data is available on the presence of laminates in post-industrial waste streams. Some substantial amounts of post-industrial multi-material flexible packaging waste should be generated as production waste. A part of this waste is directly recycled, since in these cases the recycling blend of the clean materials can function as tie-layer or filling layer. Various compatibilisers (additives) are commercially available to improve the miscibility of the blends in order to allow post-industrial recycling. The costs of these additives are not always justified and may prevent recycling, resulting in post-industrial multi-material waste.

As indicated in the previous paragraph the majority (about 68\%) of the Dutch laminates will be incinerated and the energy is recovered, the rest (about 32\%) is collected for mechanical recycling (see next paragraph). This waste management option of incineration avoids the dispersion of plastics over the planet and is robust. The main downside is the relatively high emission of carbon dioxide gases associated with the incineration [46]. For this and other reasons, it has been politically decided that plastic packaging waste should be recycled up to certain recycling targets $[47,48]$. These targets have been progressively raised, which makes the presence of non-recyclable plastic packages a growing concern for the stakeholders in the collection \& recycling schemes. Within the recently signed Dutch Plastic Pact (February $21^{\text {st }} 2019$ ) companies active in the entire value chain (from plastic producers to plastic recyclers) have committed to even more ambitious targets [49]. Material flow analysis indicates that at present the low collection response and the relatively low portion of the MSW that is subjected to mechanical recovery are the two main factors limiting recycling yields [45].

In almost the whole world apart from a few west European countries, the mixed MSW is predominantly landfilled. The quality of the landfill operation varies strongly in terms of the management of the emissions of dangerous gases, the leaching of toxic percolation fluids and the control of off-runs. Many poorly maintained landfill sites will lose much of the flexible packaging films during downpours and storms to rivers and seas. These sites contribute largely to the plastic soup problem. Therefore, the Dutch waste management system is non-representative for the rest of the world. 


\subsection{Mechanical recycling}

\subsubsection{Introduction}

Mechanical recycling refers to a multi-step operation which starts with either the separate collection of lightweight packaging waste or its mechanical recovery from mixed MSW. These plastic concentrates are mechanically sorted into tradeable sorted products for recycling facilities. The mechanical recycling facilities grind, wash, separate and dry the plastic to either washed milled goods, granulates or even compounds, which are again sold to the plastic converting industries.

In mechanical recycling the intention is that polymeric chains remain intact, enabling the polymers to be re-used several times.

Three quality decay mechanisms determine the applicability of mechanically recycled plastics: degradation (chain scission etc.), molecular contamination (odour, migration) and polymeric contamination (brittleness, haziness) [50]. For post-consumer plastic packaging waste, the degradation is often negligible due to the short use-times and for most recycled packaging waste the molecular contamination is so severe that food packaging applications are impossible (except for rPET). Together with the molecular contamination the polymeric contamination is often determining the practical application of recycled plastics made from post-consumer plastic packages. Since most polymers are immiscible, recycled plastics that contain other polymers will form immiscible blends. Although blend structures can be influenced to some extent by processing variables, in general they will worsen the optical and mechanical properties of the recycled plastics [16]. Especially for polymers with markedly different solubility parameters and melting points, such as PET and PE or PA and PE, the presence of already one percent of foreign polymer will cause the mechanical properties to deteriorate. On top of that, almost all post-consumer plastic packaging materials contain small amounts of PVC and PVdC plastics. For laminated flexibles especially, the presence of PVdC (barrier coatings) is relevant. These polymers will degrade during the processing of the recycled plastics, form hydrochloric acid which is corrosive for the equipment and speeds up the degradation of other polymers $[16,42]$. Therefore, it is the aim of many recycling operations to remove as much polymeric contaminants as possible during sorting and recycling operations and hence to obtain a recycled plastic with reasonable polymer purity that can be applied successfully.

Degradation (chain scission) or more specifically hydrolysis can occur during reprocessing of polyesters and polyamides if they are not sufficiently dried. Commonly solid state post condensation processes are used to increase the molecular mass of recycled PET and enable reprocessing into bottles and simultaneously remove molecular contaminants [51].

\subsubsection{Technical aspects}

Laminates are co-collected with other types of plastic packaging waste and lightweight packaging (LWP) wastes, although they are often listed as non-targeted packages that the consumer should not keep separate and preferably discard with the mixed MSW. In the Netherlands 4.8 kton of laminates are co-collected with 254 kton of LWP and 10.2 kton of laminates are collected with 3086 kton of mixed MSW. Hence the net collection yield is roughly $32 \%$ which is only a fraction lower than the average net collection yield for all plastic packages of 38\% [44].

Of the various types of laminates that can be discerned in waste analysis only the metal-containing laminates had a clearly reduced collection yield; only $20 \%$ of these were separately collected. The other laminates (PA-PE laminates for pre-baked breads, laminates for meat, fish, cheese, cured meats and miscellaneous laminates) all had normal collection yields. Apparently, civilians can distinguish metal-containing laminates to some extent, whereas they are unable to distinguish the other plastic laminates.

These collected LWP wastes are fed to six different sorting facilities in the Netherlands. Their combined effort gave the following distribution of laminates over the sorted product; roughly $60 \%$ ends up in the sorted product MIX, 25\% in the sorted product FILM, $10 \%$ in the various sorting residues and $5 \%$ in valuable sorting products like PP and PE (see Figure 2). This will be explained below per category of sorted products. 


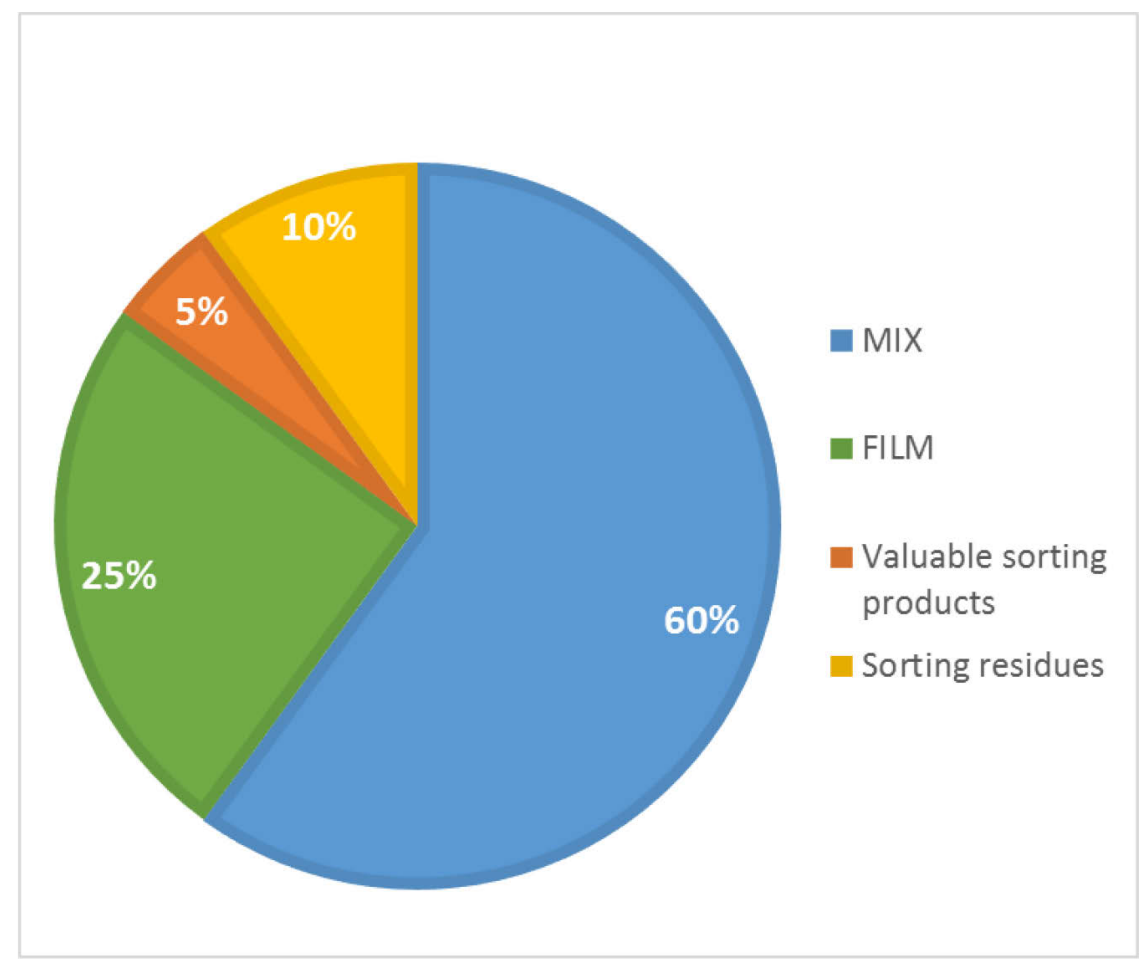

\section{Figure 2 Distribution of laminates over the sorted products}

\section{Laminates in MIX}

The laminated flexibles will mostly be recycled in the MIX recycled products. For some laminated films such as aluminium-deposited PP films and PE-EVOH-PE their presence will be considered a benefit, while others with PA, PET and PVdC will be considered a contaminant which reduces the mechanical properties of the recycled product.

\section{Laminates in FILM}

In modern film recycling plants, most of the PP-flexibles and laminated flexibles will be removed by NIR sorting machines to obtain a feedstock that is mainly composed of PE flexibles. This feedstock is subsequently washed, separated and re-granulated into a rLDPE product. In case the PE purity is higher than $97 \%$, the recycled plastic can be used to blow new dark-grey films. Additional colour sorting allows production of semi-transparent film.

In standard dry mechanical recycling plants, the feedstock is grinded, sieved, wind sifted and agglomerated. The PP-films and laminates will be incorporated in the agglomerate. These coarse agglomerates with a PE purity of only $80-85 \%$ are sold to producers of garden furniture and other solid objects.

\section{Laminates in other sorted products}

In the other sorted plastic products (PE, PP, PET bottles, PET trays) the laminated flexibles will be present in low amounts where they will raise the level of polymeric impurity and hence reduce the quality and applicability of the recycled plastic. Furthermore, their presence can cause the melt filters to block more frequently, which makes the extrusion process unstable and yields more waste products.

For the other sorted material products (beverage cartons, non-ferrous metals, ferrous-metals) the presence of laminated flexibles is just an impurity that will reduce the mass yields and raise the level of generated waste products during the recycling process. 


\subsection{Chemical and thermal recycling}

\subsubsection{Introduction}

Chemical and thermal recycling refers to processes which break down the polymers into their chemical constituents and convert them into useful products like basic chemicals and/or monomers for new plastics or fuels. Common chemical and thermal recycling methods for specific material groups are:

- Depolymerisation reactions like solvolysis (e.g. hydrolysis, glycolysis) of condensation polymers (e.g. polyesters and polyamides) to its monomers or specific oligomers

- Selective dissolution of one type of polymer from a mixture of polymers (or for the specific removal of additives) after which they can be separated and recycled.

- $\quad$ Pyrolysis of mixed plastics into monomeric and oligomeric degradation products.

- Gasification of mixed plastics into syngas

Thermal recycling is promoted by several stakeholders as an alternative processing technology for mixed plastic waste that at present has a limited value in mechanical recycling.

\subsubsection{Technical aspects}

\subsubsection{Chemical methods; Solvolysis}

The depolymerisation of PET is currently pursued by various companies such as Ioniqa and Cumapol. As an example, PET can be converted into BHET (bis(-2-hydroxyethylene) terephthalate) that can be used as a monomer in PET production. As compared to mechanical recycling the required input purity of PET is considerable lower. It is for instance possible to process both packaging waste (including PET/PE trays), contaminated non-food bottles and textile waste. Still, the input purity will affect the yield and hence the operational costs. In this process PET is recycled and all other (polymeric) substances are considered waste and will be incinerated. A major advantage of the output of the chemical recycling of PET is that the produced monomer can be used to produce virgin quality, food grade PET. Similar processes are available for recycling of PLA and can be envisaged for other polyesters.

\subsubsection{Chemical methods; Selective dissolution}

Several companies attempt to selectively dissolve one polymer from a mixture of polymers and to recycle those. Although, the polymeric chains remain intact, it is still often categorised with the chemical recycling technologies. The basic principle is fairly simple, the process technological reality is, however, much more complex with the filtration of polymer solutions and the evaporation of solvents from recovered polymers.

The most known start-up company in this field is APK with their Newcycling ${ }^{\circledR}$ technology [52]. They have explored the options to separate PA-PE laminates by selective dissolving the PE and recovering both the PE and PA.

Another selective dissolution process is the Creasolv ${ }^{\circledR}$ process [53]. Unilever has opened a pilot plant in Indonesia to process laminated flexibles from sachets and to recover the polyethylene [54]. The Creasolv ${ }^{\circledR}$ technology can also be used to recycle polystyrene while removing flame retardants [55].

\subsubsection{Thermal methods; pyrolysis and gasification}

Pyrolysis and gasification are promoted for the conversion of mixed plastic waste that is predominantly composed of polyolefins (PE, PP, PS) that cannot be recycled through chemical methods. In case of pyrolysis an oil or wax is produced as the main product, which can be re-used as fuel, feedstock or material $[36,56]$. In case of gasification syngas is obtained which can be used as an industrial feedstock to produce methanol and other chemical building blocks.

Hydrothermal processing of polymers into monomers is another form of tertiary (feedstock), chemical recycling. Yields for individual materials (e.g. for PET, PLA, PCA) are high, though not proven for polymer blends or laminates [57]. 
Pyrolysis of plastic waste has been studied by process technologists at universities and companies in the past 2 decades. This resulted in multiple review articles [16, 58-61].

The plastic waste feedstock is first pre-treated by milling and removing contaminants. Then the material is inserted in a reactor with an oxygen-free atmosphere at elevated temperatures of about $500^{\circ} \mathrm{C}$ and $1-2$ bars of pressure. This renders multiple products, a gaseous mixture, a liquid product and a solid product. The liquid is the intended product. The gas is used as fuel to run this endothermic process and the solid is either a waste product (tar) or low-income side product (char).

The composition of plastic waste feedstock has a great influence on the type of products that are formed. Heteroatoms $(\mathrm{O}, \mathrm{S}, \mathrm{Cl}, \mathrm{N}, \mathrm{Br}, \mathrm{P})$ in the feedstock are in principle undesired for multiple reasons: the formation of corrosive gases $(\mathrm{Cl}, \mathrm{Br}, \mathrm{S})$, reduction of yield $(\mathrm{O}, \mathrm{N})$ and the undesired accumulation of these elements in the liquid product. Hence, especially laminated flexible films containing other materials than polyolefins would be an undesired type of feedstock for pyrolysis.

\subsection{Organic recycling}

\subsubsection{Introduction}

The development of biodegradable packaging including multi-material laminates is receiving much attention and this is boosted by environmental issues with respect to littering and "plastic soup". Still, experts do not believe that biodegradable packaging is the single solution for these issues but could have benefits in specific applications [62]. Examples are bags for the collection of organic waste, packaging products that after use contain large amounts of organic residues (teabags, coffee capsules) and various products that are used in agriculture or are likely to end up in nature. In biodegradation it is important to discriminate between uncontrolled (littering) and controlled environments (industrial composting, anaerobic digestion). Controlled environments through specific waste collection and waste treatment processes are highly preferred. Setting criteria for biodegradation indicating the biodegradation conditions (environment), time limitations and prohibiting the use of additives/substances that can be harmful for the environment is a prerequisite. Moreover, standard methods and certification schemes need to be in place to measure and ensure actual biodegradation in the specific waste treatment system. A good example is the EN13432 [63] standard and certification via the Seedling logo. The three main criteria of the EN 13432 standard are:

1. Biodegradation should be complete to natural occurring gasses, water and biomass

2. Disintegration should be sufficiently fast and compliant with industrial practice

3. Product should have no negative effect on the (composting) process and the quality of the compost.

The first criterion defines the polymer types and prevents the formation of micro-plastics. The second criterion sets the size of the packaging product and the third criterion prevents the use of harmful components/additives like heavy metal containing printing inks.

\subsubsection{Technical aspects}

The organic recycling of biodegradable multi-material laminates is feasible from a technical perspective. Combinations of biodegradable materials will still biodegrade. The use of $\mathrm{AlO}_{\mathrm{x}}$ and $\mathrm{SiO}_{\mathrm{x}}$ barrier coatings is not restricted as $\mathrm{SiO}_{x}$ is a naturally occurring substance and aluminium (in the low concentrations used in $\mathrm{AlO}_{x}$ coatings) is considered a trace element that is necessary for biological activity. All packaging components need to comply with EN13432 (labels, glues and inks) since the final packaging product needs to be certified. Biodegradable paper laminates can also be recycled via organic routes provided they fulfil the criteria of EN13432. Moreover, food residues do not have to be washed off. Organic recycling via industrial composting will result in compost, a valuable resource that can be used as a substitute for peat (peat is not renewable). Using anaerobic digestion, methane gas can be produced. 


\subsubsection{Practical and economical limitations and acceptance}

The most logical route for the collection and recycling of biodegradable (compostable) plastic packaging would be together with (post-consumer) organic waste. Despite standards and certification schemes that state that packaging products that comply to EN13432 can be disposed of with organic waste, this is not commonly accepted by municipalities and companies responsible for treatment of organic waste. This is due to various factors like for example:

- limited understanding of the EN13432 standard and the biodegradation process, leading to misconceptions,

- (fear of) pollution of organic waste with fossil non-degradable plastics,

- changes in industrial composting processes and lack of information how this influences the behaviour of certified compostable packaging materials.

At present various stakeholders are involved in a project that will measure the effect and fate of specific compostable plastic packaging products in a representative full-scale composting facility. The aim is to set-up a positive list of products that are allowed in organic waste. This positive list focusses on products that help to increase the amount of food waste collected to be composted (co-benefit) and not on plastic products that are difficult to recycle like laminates. Typical products that are considered on the positive list would be teabags, coffee pads, coffee capsules and collection bags for organic waste.

Improved labelling is needed to minimize sorting errors by consumers. KIDV designed a label for this purpose, indicating that the specific packaging should be disposed of with organic waste, but at present this is not communicated due to discussions on acceptance. Additionally, changing the appearance of the packaging and the specific use of biodegradable packaging for food products that are associated with organic waste will help consumers with correct disposal of biodegradable packaging products.

Industrial organic waste which contains compostable products is widely accepted for a separate treatment. Companies like Attero indicate that PLA disposables collected at festivals generate a favourable amount of methane in anaerobic digestion processes.

The main economical limitations are associated to the testing and certification of biodegradable packaging products. Still, this is necessary to prove the recyclability of these products. In principle adaptations (additional sieving and milling) in organic recycling processes are not necessary. Current issues with plastic pollution are not associated with biodegradable plastics but with non-degradable fossil-based plastics.

In the "EU Roadmap for a Strategy on Plastics in a Circular Economy" the transition from a linear to a circular economy is pursued via decarbonizing the plastic economy and an increased efficiency of waste management with a strong focus on recycling of plastics [2]. In this strategy organic recycling is missing as a valuable recycling route. Still, separate collection of bio-waste and organic recycling will help to improve the quality of other waste streams as well as the efficiency of waste management altogether[64]. At present multi-material flexible packaging products are not mechanically recyclable and may even disturb mechanical recycling of other packaging products. In this perspective organic recycling can offer a valuable alternative for multi-material packaging. 


\subsection{Paper recycling}

Several paper-plastic-laminates and paper-plastic-aluminium-laminates are on the market for dry food products, herbs and tea products, etc. Although civilians are not encouraged to discard these laminates with paper \& board, it is likely that several of them will end-up in this collected stream. Since the amounts of collected paper \& board are relatively large as compared to the amounts of paper-based laminates, they will simply be one of the many small impurities for the complete recycling system and currently hardly relevant. This might, however, change in the future. Since, consumers perceive paper as sustainable, this could encourage producers to use paper-based-laminates. Paper laminates should not be processed in conventional paper mills. It is unlikely that the laminates will disintegrate and hence they will only contribute to the plastic waste fraction that has to be incinerated. Also, paper-based laminates used for food packaging can contain food residues that cause contamination with microorganisms and can attract pests. The paper-laminates could better be treated with beverage cartons in a dedicated recycling facility, where the laminates will disintegrate and contribute to both the recovered paper pulp and the plastic-aluminium-rejects. To allow the paper laminates to be recycled together with beverage cartons, large changes are required in the collection and sorting processes. Several stakeholders are expected to oppose such changes, nevertheless from an overall material recycling perspective, this might be a good suggestion. 


\section{$5 \quad$ Stakeholders}

\subsection{Introduction}

Improving plastic recyclability and promoting the development of a circular economy require cooperation throughout the entire value chain. Governmental support for guidance and financing is needed also since global actions/developments are needed. Moreover, most participants in the value chain are supplying the global market.

The main stakeholders (in categories) are:

- Government; Dutch (national \& local) and European,

- Plastic producers \& converters (including laminate producers),

- Food producing companies (that apply laminates),

- Retail,

- Civilians,

- Waste management, sorting \& recycling industries.

Their positions will be discussed below in separate paragraphs. The information is based on publicly available information, supplemented with information from over 10 interviews and discussions with food companies that use laminated flexibles as packaging material for their products.

\subsection{Position of the government}

At present the European government is very active in setting circularity goals (see paragraph 1.2 ) and these are or will likely be adopted by the national governments of member states. The primary focus of plastic packaging waste policies was to increase the recycling rates and to lower the specific amounts of mixed MSW produced per inhabitant. The waste directive of the European Union has the waste hierarchy as leading principle, which implies that member states are forced to divert MSW from landfill sites, to establish waste sorting and recycling facilities and to erect incineration facilities. Policy studies showed an increasing gap between member states with regard to compliance to this waste directive's diversion from landfill [65]. The growing awareness of the Plastic soup problem and the dispersion of plastics into the environment in general caused the European commission to write a Plastic Strategy [66] in which legislation is proposed that will force producers to only place plastic packaging objects on the market that is either reusable or easily recycled. A possible interpretation of this text is that laminated flexible packages, which are non-recyclable almost by definition, need to be redesigned to be recyclable or must be replaced by mono-material packages.

\subsection{Position of the plastic producers and converters}

Industries have positively responded on the challenges set, by themselves or through various associations including:

- Plastics Europe representing plastics manufacturers,

- European Plastics Converters (EuPC),

- $\quad$ European Plastics Recyclers (PRE).

Plastics Europe has published "Plastics 2030"; making Circularity and Resource Efficiency a Reality [67]. This voluntary commitment translates overarching goals into specific targets (see Table 2). 
Table 2 Summary of the plastics 2030 strategy of Plastics Europe.

\begin{tabular}{ll} 
Overarching goals & Targets \\
\hline Prevent leakage of plastics into the environment & By increasing engagement inside and outside the plastic industry \\
\hline Improve resource efficiency & By accelerating innovation in the full life cycle of products \\
\hline Improve circularity of plastic packaging & $\begin{array}{l}\text { By reaching } 100 \% \text { reuse in 2040, recycling and/or recovery of all } \\
\text { plastic packaging in the whole EU. } \\
\text { In 2030: } 60 \% \text { reuse and recycling of all plastic packaging }\end{array}$ \\
\hline
\end{tabular}

As can be seen from the table, targets on littering and resource efficiency are not very specific and less ambitious as targets set by the European Government and by individual companies (multinationals). In these targets clear definitions for recycling and recyclability are needed. The definitions as proposed by international plastic recycling groups are listed in section 1.3.

Many plastic producers \& converters have signed The New Plastics Economy Global Commitment (see section 1.2). As a response to these commitments and targets the debate has started on simplifying plastics and phasing out certain categories from certain uses (e.g. polyvinyl chloride, polystyrene from packaging) [68]. Simultaneously "new" plastics and compostable plastics like PLA are under debate since they do not fit within current collection \& recycling systems and their initial volumes are low. Potential benefits of including alternative materials to the recycling system are disregarded. Also, the shortcomings of the current plastic system are hardly acknowledged and there is no clear and broadly supported roadmap to progress towards a more circular recycling system. Plastic producers \& converters are open for the development of bio-based drop-in materials that are chemically identical to current bulk plastics (e.g. bio-PET and bio-PE).

With respect to laminates, producers aim at developing novel (barrier) laminates that can be recycled with (PE) film products. The development and marketing of paper-based laminates and/or laminates that are biodegradable and/or compostable as a solution for current recycling issues (and sometimes littering), is ongoing and mainly promoted by smaller and medium size companies.

\subsection{Position of food producing companies and retail}

Food producing companies like Nestlé and Unilever have set strict recycling targets. Most food companies have announced that they strive to redesign their plastic packages to have them either reusable, recyclable or organically recyclable before the end of 2025 . How to accomplish this with laminate flexible packages is still an unresolved issue. Options that are frequently mentioned when interacting with this type of companies are:

- Replacement of metallised packaging products with EVOH containing packaging,

- $\quad$ Replacing PET/PE laminates by (talc filled) PP/PE laminates

- Replacing PA-PE laminates by SiOx-PP films

- Introducing paper-based laminates,

- Biodegradable barrier laminates.

The companies are restricted by the availability of recyclable laminates, and often scientific proof on recyclability is missing. Still, retail has introduced the topic recyclability of packages in their procurement conditions [69]. In the discussions between food companies and retailers, increased prices and/or shorter shelf life because of phasing out laminates were generally considered not acceptable by retail. Topics like food sourcing (sustainable), preventing food waste and sales (marketing) are still more important for retail.

During the months November 2018 -January 2019 we had over 10 interviews and discussions on the new demand to use recyclable packages with food packaging companies that utilise laminated flexible packages. We made the following observations:

- No food company had a final plan to deal with the recyclability of the laminated flexibles,

- Companies that use only one type of laminated plastic package already had identified an alternative packaging type that might be suitable. When asked for scientific proof of 
recyclability of the alternative package, the food companies had none and told that they rely for this on the packaging companies.

- Companies that use multiple laminated plastic packages had only partial action plans. Some focussed on the laminates for the largest products. Other food companies focussed on dedicated laminates that were only used by them and hoped the other laminated flexibles will be dealt with by packaging companies.

\subsection{Position of civilians}

Scientific studies on the consumer perception of laminated flexible packaging are scarce [41]. Generally, they do not appear in the packaging-irritation-top 10's which are usually filled with packages that are difficult to open or that are relatively large as compared to the contents, so they apparently do not cause the largest share of dissatisfaction. In general, laminated flexible packages are lightweight and render the food products relative long shelf lives, which are typical consumer benefits that are likely to be appreciated.

In the United Kingdom consumer organisations have protested against the non-recyclable nature of crisp bags [70] and in consequence the largest UK crisp manufacturer commenced a voluntary sendback recycling system[71] and also the company Terracycle started a return system [72]. These examples reveal that the position of civilians towards laminated flexible packages can change depending on the focus given by the media.

\subsection{Position of waste management, sorting and recycling industries}

The waste management companies involved with incineration have no issues with laminated flexible packages. In general, they will raise the caloric value of the waste and hence will improve the thermal recovery rate. They will only be less positive with respect to chlorine-containing laminates (PVdC and PVC containing) since incineration will cause the formation of hydrochloric acid and this can cause corrosion in their installations.

Sorting companies of lightweight packaging waste consider laminated flexible packages to be contaminants. Especially the aluminium-containing flexible packaging films are defined as a contaminant that belongs to the waste category 'other residual materials' for which there are concentration limits in the sorting specifications. Hence, for the sorting companies this is a problematic packaging category, for which they must control the concentration in their sorting products.

Recycling companies of PET bottles, PE, PP and Film will regard the presence of laminated flexible packages as a contaminant that will introduce polymeric contamination into their recycled plastics and hence must be avoided. Furthermore, aluminium-containing laminates are regarded as the main culprit for melt-filter blockades and process instability. The reason is that plugged melt filters show many metallic particles which are claimed to originate from these aluminium-containing laminates. Although it is likely that these aluminium-laminates do contribute to this problem, the melt filter will also plug because of the presence of laminates which contain other polymers with high melting temperatures (PA, PET), etc. And last, the metal-containing laminates will trigger the metal-detecting equipment that is placed before sensitive equipment such as mills and extruders, creating material losses. A better discrimination by the metal detectors between the real solid metal objects, laminated flexibles with massive aluminium-layers and laminated flexibles with deposited aluminium-layers is desirable, since the latter category is most probably not detrimental for extruders and melt filters. Recycling companies of MIX will in general consider the laminated flexible packages as a feedstock. One representative of a MIX recycler claimed that he likes to have crisps bags in the MIX, since their presence improves the mechanical properties. 
Stakeholders involved with processing of both organic and plastic waste do not accept biodegradable barrier laminates as a solution for current recycling issues with laminate packaging. In both cases a potential increase in polymeric contamination of these waste streams is used as the main argument to oppose the introduction of such laminates.

\subsection{Industrial challenges with respect to laminates}

Despite the willingness of industry to move to sustainable and recyclable packaging products there are numerous challenges with respect to flexible laminates for packaging applications. The main questions are summarised below:

Definitions:

- What is the definition of recyclable?

- To what extent is the quality of the recycled materials and the goals we want to achieve with those recycled materials included into the definition of recyclable?

- Which laminates are recyclable and how is this proven (practically and scientifically)?

Solutions:

- What packaging products can replace current high-performance laminates? What are their benefits and what are their drawbacks (economically and environmentally)?

- Can alternative laminates offer the same functionality with respect to processing on packaging lines and with respect to shelf-life? And if not, is the reduced shelf-life then still acceptable within the product logistics and doesn't it result in more product loss (food loss).

- What is the availability of alternative laminates? (Are these alternatives true alternatives; do they offer a meaningful advantage?)

- What are the requirements with respect to sorting, are adaptations in sorting schemes and/or sorting equipment necessary?

- What should be the target sorting product of a laminate?

Strategy:

- Which type of solution should be prioritized: avoiding the use of laminated flexibles, redesigning the multi-material laminates or adjusting processes to make existing laminates more recyclable?

- Which technological developments will have a major impact on laminate products within the coming 5-10 years (both in recycling technology and in material technology)?

- How do we manage global issues when products are sold to countries without a closed waste management system or with other regulations than in Europe? (For example, how to deal with PVC, which is still considered a sustainable packaging material in Asia?)

- What is the impact of the negative image of plastic packaging on the future of plastic packaging products and more specific on plastic laminates?

- How to deal with the myriad of collection \& recycling systems in Europe?

The research questions that can already be answered with the current knowledge will be answered in the next chapter. The other research questions will have to be answered based on future research. 


\section{Discussion; improving end-of-life options of flexible laminates}

\subsection{Introduction}

The urgency to develop a more sustainable, circular plastics industry is clear for most stakeholders involved. However, stakeholders often have different priorities and different ideas about a circular economy for plastic packages. Therefore, there is no widely shared roadmap of the steps that need to be taken to reach that circular economy.

Also, the whole concept of a circular economy for the plastics industry still needs to be developed. Laminates (multi-material, flexible packaging products) are a distinct but small group of packaging products that by nature are either more difficult to recycle than mono-material packaging products, or even impossible to recycle. This chapter summarises strategies towards circular laminates including comments on their feasibility with respect to technical, economic and social aspects (acceptance). Also, comments on environmental benefits and drawbacks are indicated.

\subsection{Strategies}

All the strategies that stakeholders are (considering) working on can be categorised in four main categories, which, ordered in line with the waste hierarchy model, renders the following list [73]:

1. Avoid using laminated flexible packages.

2. Redesign the laminated flexible packages to new flexible packages that fit in one of the existing recycling schemes.

3. Redesign one of the current collection \& recycling schemes to fit the existing laminated flexible packages in.

4. Improve the sort-ability and recognisability of existing laminated flexible packages to reduce the negative impact of existing laminated flexible packages in existing collection \& recycling schemes.

This hierarchal list is further expanded and elaborated on in the following paragraphs.

\subsection{Avoid the use of laminated flexible packages}

\subsubsection{General approach}

Avoiding the use of laminated flexible packages is the first measure that should be considered. To assess the viability of this measure, the following aspects should be verified:

a) Verify that there is a sound technical reason for using a laminated flexible package.

b) Verify that the shelf life of the product in the laminated flexible is substantially longer than in a mono-material PE based film, which translates in less product-loss for the products packaged in laminated plastic films.

c) Verify that the protective function that the laminated film offers cannot be substituted by protective additives in the food product.

d) Verify that the shelf-life is truly required and explore the possibility for a fresh, short-life product alternative in a mono-material package which fits in the logistical systems that are in place.

In all cases additional environmental impacts should be avoided as much as possible. 


\subsubsection{Additional comments on this strategy}

Currently most laminates are used for a solid technological reason regarding shelf-life extension provision of protection to the packaged goods. However, for a small group of laminate applications, there is no solid technological reason to use a complicated film structure. The use of laminates can be historical and has not been challenged or changed anymore. Also, in some cases the marketing department requires a metallic look for the packaged product, that has been executed with a laminated film. For these cases it would make sense to reconsider the laminated flexible films applied and to explore the option of using a standard PE flexible instead.

In a few other cases, the protection of a food product can either be effectuated by adding protective additives to the food product or by using a multi-layered barrier packaging material. Well known examples are fruit juices which are prone to oxidation and to which either anti-oxidants (like vitamin C) could be added or could be packaged in barrier bottles without additives. In the past decades a reverse trend was noticed, in which less additives were used by the food companies to produce more authentic food products. This 'clean label' trend is still relevant and going against it may be an opportunity for some products but needs careful explanation.

In a few other cases it might be possible to change the whole concept of packaging, product and logistics. For instance, pre-baked bread products are currently sold in PA-PE packages and the modified atmosphere keeps the bread products protected against mould growth for 6-8 weeks. Some pre-baked bread products are, however, sold as fresh products with a shelf life of maximally one week. These fresh pre-baked bread products can simply be packaged in a PE bag and hence do not require a laminated film. However, the whole logistical concept must be changed, to avoid the generation of large amounts of food waste, which will have substantially more environmental impact than the laminated flexible film itself.

For other applications, avoiding the use of laminated flexibles would imply an increased used of packaging materials, like for instance in the redesign from stand-up pouches to plastic pots, glass jars and metal cans. At present the recycling of glass and metal packaging is more advanced and feasible as a 'permanent material'. Still this would involve increased costs of packaging and logistics and would cause additional environmental impacts. Avoiding the use of laminated flexibles is technically feasible for products like pouches for soups and sauces but not for packages for fish products and cured meat products, which rely either on vacuum packaging or modified atmosphere packaging. For these products avoiding laminates would imply a reduced shelf life that can cause food spoilage, again contributing to costs and environmental impact.

\subsection{Redesign the laminates to new flexible packages that fit in one of the existing recycling schemes}

\subsubsection{General approach}

If the use of laminated flexible packages cannot be avoided, changing their design to make them fit in one of the existing recycling schemes is a next option. This could be mechanical recycling, organic recycling or paper recycling, depending on the specific redesign. Within the mechanical recycling system, various redesign routes can be envisaged like the development and use of barrier-layers and tie-layers that are fully compatible with PE film recycling or the development and use of water-soluble barrier and tie-layers that are removed during mechanical recycling.

\subsubsection{Additional comments on the development of mechanically recyclable laminated flexible packages}

\subsubsection{Laminated films that can be recycled with PE films}

Several plastics and converting industries are busy to develop new resins and new laminated film structures which could be recycled with PE film to a recycled LDPE product. A few companies claim to 
develop a mono-material laminate structure of different grades of PE which would render a film with both gas and moisture barrier properties[74, 75]. In case this new laminated film structure would indeed be composed of only one type of polymer (PE) and the material is easily sorted and mechanically recycled, this would be a great option. No technical evidence for this claim has been put forward yet.

Other flexible packaging companies are busy with developing $\mathrm{EVOH}$ and $\mathrm{SiO}_{\mathrm{x}}$-based alternatives of which they claim that these films are completely compatible with PE film recycling. This could be a proper strategy in case it has been proven that these new laminated structures are recyclable with PE films and do not infringe on the applications of this recycled plastic material. Several flexible film companies currently promote new laminated film materials as 'circular' or as 'recyclable. However, no technical evidence for these claims are given and hence care should be taken.

Several PE-EVOH-PE laminate films are promoted as recyclable since they are composed of more than $95 \%$ of PE and hence comply with a legal limit in a Swedish law. This, however, does not imply that these laminates are recyclable and do not lower the quality of recycled PE film.

Another company succeeded in making a barrier film based on $\mathrm{SiO}_{x}$ deposited on PP and or PE films[76]. Although quite an achievement from a production point of view, it is unclear if all these laminates are recyclable. The $\mathrm{SiO}_{x}$ layer presumably doesn't interfere with the mechanical recycling processes, as it has previously been demonstrated that the $\mathrm{SiO}_{x}$ deposited on PET bottles doesn't interfere with the PET bottle recycling process. Hence in case a PE-SiO laminate is produced without additional layers of PET or other polymers, the film is likely to be recyclable with PE films, although it should be noted that the polyolefin recycling in certain aspects differs from PET recycling. In case the base layer is PP film, the film will cause polymeric contamination with PP in PE film products, unless NIR sorting machines remove it.

\subsubsection{The use of water soluble tie-layer/barrier materials}

There are some examples of water soluble barrier materials, like PVOH/PVA [77] that are currently applied in laminated film structures with a gas barrier function. Compared to other barrier materials this material is rather expensive and more difficult to process. Currently only a limited amount of film suppliers is offering high-performance barrier films that are based on these barrier layers. Since some of these films are targeted for the cured-meat packaging markets, apparently high barrier laminated film structures can be made with these resins.

Although in general barrier materials like PVOH are known to be water-soluble, it needs to be tested that these resins also dissolve during the mechanical recycling process. Furthermore, the sealing layers will need to be produced from PE to make the film compatible with the PE film recycling process and all other packaging components (glue, labels) will need to be made from water-soluble resins (more precisely the resins need to dissolve in hot alkaline solutions). Although still much development work is required to establish full-compatibility with the current sorting \& recycling scheme for plastic packaging waste, the prospect for this solution is good.

\subsubsection{Additional comments on laminates in organic or paper recycling}

\subsubsection{Compostable laminates}

In organic recycling, plastics laminates containing multiple biodegradable materials (plastics and papers), even with $\mathrm{AlO}_{x}$ and $\mathrm{SiO}_{x}$ coatings can be processed. Various compostable barrier laminates are currently commercially available. Some still contain PVdC coatings although this is not in line with the EN13432 standard. Those based on metallised films are viable substitutes for packaging various food products. The main hurdle is their acceptance by waste management companies. A successful implementation would involve gaining the acceptance to let civilians discard these laminates in organic waste. At present the potential acceptance of specific compostable packaging products that contain or help the collection of organic waste is studied and discussed. An important issue at present is the (increasing) contamination of organic waste with non-degradable plastic (packaging waste). This has led to the installation of sieves to remove plastic waste (including compostable products) before the organic waste enters the composting facility. 


\subsubsection{Paper recyclable laminates}

An increased use of paper-laminates, accompanied with the acceptance of these paper-laminates in the related waste streams of either paper \& board and beverage cartons, could be a relative simple solution if the incumbents would accept the addition. Since the paper fibres are relatively enclosed in the laminate structure, disintegration seems to be more appropriate in a beverage carton recycling facility than in a conventional paper mill. This would imply that the paper laminates would have to be discarded with the lightweight packaging waste and sorted into the beverage carton sorted product. The paper would then be reused, and the plastic-aluminium rejects would then be used in cement kilns as fuel. The co-operation of the incumbents with this transition is unclear.

\subsection{Change the collection, sorting \& recycling processes to fit in existing or novel laminated flexible packages}

\subsubsection{General approach}

A fundamental difference with the previous approach is that this strategy needs investments of stakeholders involved in waste management and recycling rather than in laminate production or use. These investments should be justified by volumes, profits, environmental benefits etc. Various strategies can be envisaged:

- Operate a mono-collection system for laminated flexibles.

- Create a new sorting category for aluminium-containing laminated flexibles and process them separately.

- Create a new sorted product for paper-containing laminated flexibles and process them separately (or combine with beverage cartons).

- Create a new sorted product for organic recyclable packaging where organic recyclable laminates fit in.

- Develop and use new layer separation processes.

- Improve the properties of laminates using compatibilisers.

- Further develop chemical recycling for processing laminates.

- $\quad$ Further develop thermal recycling for processing laminates.

- Design-from-recycling; use compatabilisers and change process parameters to make valuable products from laminated flexibles.

\subsubsection{Additional comments on these strategies}

\subsubsection{Mono collection of specific laminates}

Mono collection of metallised PP laminates for crisps was recently introduced by Walker in the UK[78]. Collected packaging waste will be used to produce roofing, flooring, trays and outdoor furniture. Still, mono collection of specific packages is very expensive, and the environmental benefits seem limited.

\subsubsection{Create a separate sorted product for aluminium containing laminates}

Aluminium-containing laminates (both deposited and massive) are present in the currently collected lightweight packaging waste, although collection agencies and municipalities have asked civilians not to collect them separately (see paragraph 4.2). Currently, these laminates end-up in various sorted products, where they are currently regarded as contaminants. If these aluminium-containing laminates would be sorted in a separate fraction (metal containing films), then they could be recycled into various objects varying from roofing tiles to appliance housings. This would however require the development of dedicated sorting technologies and recycling technologies.

\subsubsection{Create a sorted product for paper laminates}

This strategy is related to the paper recyclable laminates discussed in paragraph 6.4.3.2. A separate category for paper laminates could be created for the sorting of lightweight packaging wastes and 
these laminates could be recycled separately. Alternatively, these paper laminates are sorted to the beverage carton product and simultaneously processed with this material.

\subsubsection{Create a new sorted product for organic recyclable packaging}

This strategy is related to the organic recyclable laminates discussed in in paragraph 6.4.3.1. Advantages of a separate sorting category for organic recyclable products are that larger volumes of compostable packaging can be created that can be processed separately from organic waste to produce methane. Moreover, the system does not rely on accurate disposal by civilians. Acceptance of this strategy by waste companies involved in plastic sorting is the main hurdle as they fear pollution of other sorting products by compostable plastics. This risk of pollution may be overrated as compostable plastics can be removed using both NIR sorting and density separation. This implies that a PLA based barrier laminate could be removed more easily than a PE-PA or PE-PET laminate.

\subsubsection{Separate the laminate layers and recycle them separately}

Good adhesion of laminate layers is often required to obtain sufficient functionality of the laminate. For this purpose additional tie-layers are frequently used. Consequently, separation of laminate layers is technically difficult and will significantly add to the costs. Moreover, not all layers are separable (like $\mathrm{SiO}_{x}$ and $\mathrm{AlO}_{\mathrm{x}}$ ) so this strategy may not be applicable for all laminates. Once the different polymer layers are separated the main polymeric components can be recycled. Usually, these are the relatively larger sealing layers from PE and PP, which can be used to create a mixed polyolefin product. The smaller fraction will be the barrier polymers (PA, EVOH, PET, etc.) which can be collected as sinking fraction. This mixed sinking fraction can probably not be reused as a recycling product. Examples of this strategy are the processes of APK and Creasolv, which are either in development or tested in pilot facilities.

\subsubsection{Improve the properties of laminates using compatibilisers}

Using specific compatibilisers, the properties of PE/PA blends, PE/PET blends and many more polymer combinations can be improved[12-16, 79, 80]. How this affects mechanical recycling of film products is unclear. Also, it does not solve current issues with metallised films and specific barrier materials like PVdC (thermal instability and acid formation) so is only applicable for certain categories of laminates. For more complex mixtures, compatibilisation needs to be developed further. Compatibilisers significantly add to the costs of recycled plastics. They can offer improved recyclability but not always circularity. For instance, a mixed recycled plastic can be made from the sorted product MIX containing these laminated flexibles by adding compatabilisers to improve the quality, but the question is if the improvement in mechanical properties will be sufficient to pay for the added costs.

The use of compatibilisers can be regarded as one type of technical intervention that helps to create higher performance materials for recycled feedstocks. Other interventions are adjusted processing parameters to optimise the blend structure formation. These strategies are occasionally referred to as design-from-recycling [81].

\subsubsection{Chemical recycling}

Only PA and PET based laminates are potentially interesting feedstocks for depolymerisation reactors. However, most laminated films that contain either PA or PET have a minority share of these layers and a majority of sealing layers of PE and CPP. Hence, this can only be an attractive option for a recycling company if the residues can also be sold, as PO-mix. This appears to be attractive only for postindustrial laminate wastes with known compositions. This doesn't appear to be attractive for sorted products made from post-consumer laminates, since various types of polymers will be present and only mixtures of monomers and sealing polymers will be retrieved.

\subsubsection{Thermal recycling}

Pyrolysis of plastic packaging waste is being studied, but no company has delivered a turn-key solution yet that is economically and ecologically sound. One issue is the formation of toxic side products of high concern. Another issue is that the produced pyrolysis oils do not comply with the 
specifications regarding sulphur, nitrogen, phosphor and chlorine-content etc. The introduction of heteroatoms plays an important role in this. Hydrogenation of the pyrolysis oils alleviates these quality issues to some extent. Since laminated flexible packaging films are relatively rich in heteroatoms, this feedstock does not appear to be attractive for thermal recycling processes. Finally, thermal recycling is considered costly due to high energy input and relatively low yields.

\subsection{Make unavoidable non-recyclable laminate better recognisable and sortable}

\subsubsection{Comments on this strategy}

For many applications, the use of laminated flexibles cannot be avoided without causing a large environmental impact in the form of food losses. Additionally, these laminates cannot always be redesigned into a new material which is proven to be fully compatible with the current sorting and recycling industries. A fall-back option is to make them better recognisable and sortable. This is a relevant option for all those laminates that contain materials that are proven to be non-compatible with PE, hence PET, PA, Aluminium, PVC, PVdC and perhaps also EVOH, SiOx, PVOH etc. These laminates can be coloured in a specific colour that will allow the rapid sorting of these materials. Also, a marker or tracer could be added (fluorescence, or XRF based). This improved recognisability will allow for a circular reapplication of the sorted product FILM if other contaminating film products like PP and PET are also removed. To render this strategy successfully it is required that this improved sortability will be harmonised with many film-producing and food-packaging companies, so that it can reliably be applied by sorting companies. Applying the strategy to other non-PE film packaging products (PP, PET)

\subsection{General recommendations}

Currently there are many open questions for all stakeholders. However, two questions prevail;

- Is there a precise definition of recyclability to test laminated flexibles against?

- Is there a test method to verify if newly developed laminated flexibles are recyclable? Therefore, it is our general recommendation that those questions are answered by an independent authority.

Recently PRE-RecyClass released an evaluation protocol for flexible plastic packages that addresses both questions [82]. The basis for these evaluation scheme appears to be industrial know-how of incumbents. Although, this protocol is good first step forward, it still leaves a few questions unanswered; what is the targeted market for recycled film product made in accordance with this protocol and do all stakeholders agree with this interpretation. 


\section{$7 \quad$ Conclusions}

Laminated flexible plastic packages form approximately $4 \%$ of the plastic packages and are concentrated in sorted products such as sorted MIX and sorted Films in concentrations of 10-15\%. These laminated flexible packages are composed of multiple polymers and materials and hence by their very nature are not-recyclable in a circular manner to new flexible film products. Additionally, these laminates disperse over all the sorted products and although in most cases only present in low concentrations, still cause polymeric contamination in those recycled plastics. Hence their presence reduces the recyclability of well recyclable bottles, flasks, trays etc. This hinders the progress towards a more circular economy for plastic packages.

On the other hand, these laminated flexible plastic packages serve an important role in our society, by protecting the quality of food products and rendering these food products sufficiently shelf-stable to allow for central production and distribution. To reduce the impact of the laminates on the plastic recycling systems, a stepped approach is recommended (see Figure 3). First, producers should verify that the laminates are truly necessary and cannot be avoided. Secondly, design-for-recycling approaches should be tested to allow for a smooth integration in the current collection and recycling system. Thirdly, changes in the collection, sorting and recycling processes should be tested to evaluate if the laminates cannot fit into adjusted collection \& recycling schemes. When all these options fail, the laminate should be redesigned to be much more easily recognized and sorted. Hence in the latter case, the benefit of laminate in the supply chain is acknowledged and it is accepted that these packages are unfortunately still not recyclable, but to avoid polymeric contamination, the design of the laminate is altered in such a manner that it is efficiently removed, added to the sorting residues and incinerated. Accepting that a small fraction of all the plastic packages have an important function but can still not be recycled in a circular manner, is vital to improve the quality of the recycled plastics made from packages that are circular recyclable.

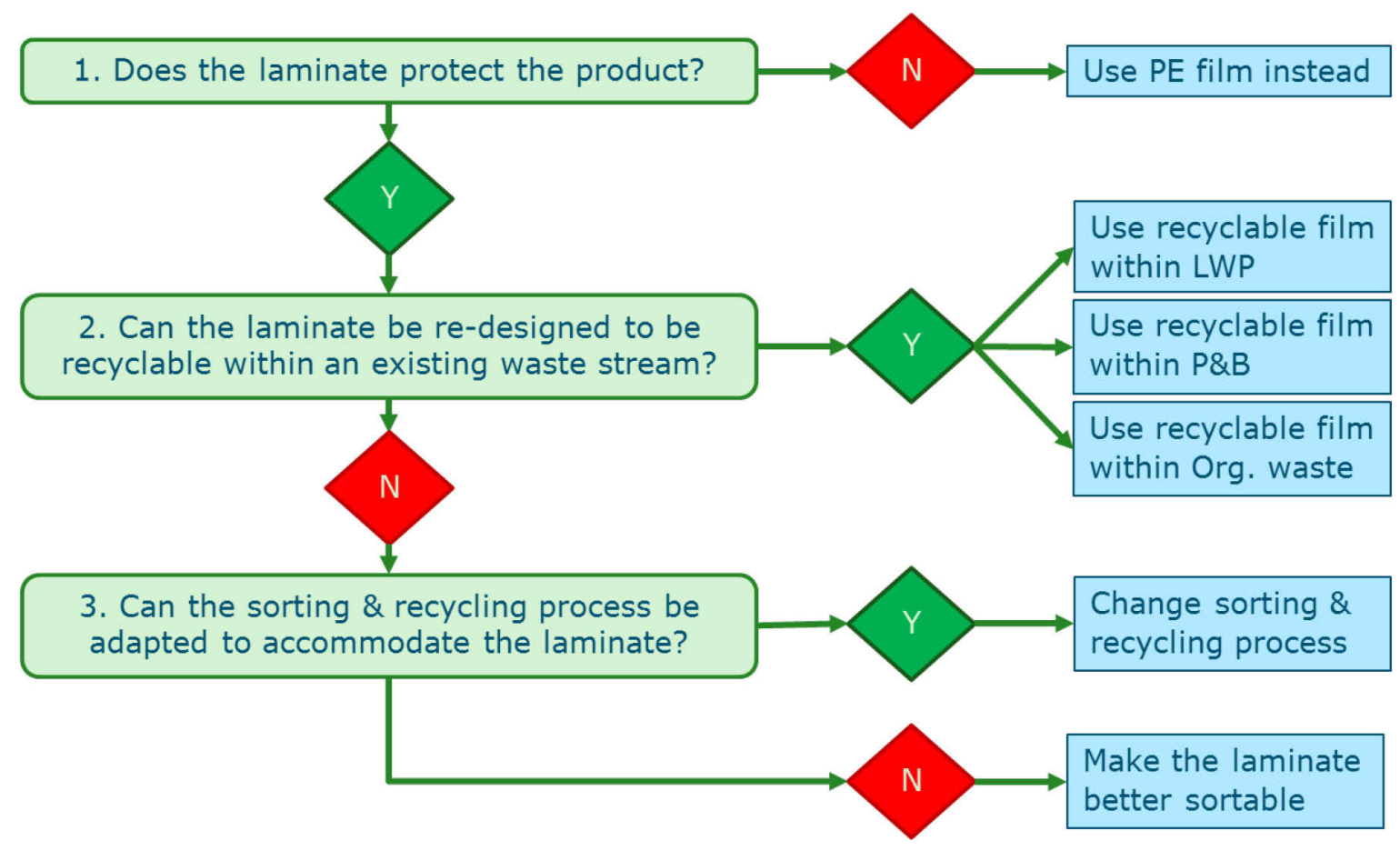

Figure 3 Towards circular laminated flexible packages

As a first step (agreement on) a precise definition of recyclability is needed to allow evaluation of the recyclability of laminated flexible packages. This implies that a test method is needed to verify if newly developed laminated flexibles are recyclable. 
1. www.ellenmacarthurfoundation.org/our-work/activities/new-plastics-economy. 2017.

2. www.plasticseurope.org/en/focus-areas/strategy-plastics. 2018.

3. www.rijksoverheid.nl/documenten/kamerstukken/2018/03/10/naar-een-circulaireverpakkingsketen. 2018.

4. https://www.ellenmacarthurfoundation.org/news/spring-2019-report0-. 2019.

5. www.circulairondernemen.nl/uploads/15fbc61dcb989170711acd191ed6c931.pdf. 2019.

6. https://www. plasticsrecyclers.eu/international-plastic-recycling-groups-announce-global-definitionplastics-recyclability. 2018.

7. Kirchherr, J., D. Reike, and M. Hekkert, Conceptualizing the circular economy: An analysis of 114 definitions. Resources, Conservation and Recycling, 2017. 127: p. 221-232.

8. Saidani, M., et al., A taxonomy of circular economy indicators. Journal of Cleaner Production, 2019. 207: p. 542-559.

9. Linder, M., S. Sarasini, and P. van Loon, A Metric for Quantifying Product-Level Circularity. Journal of Industrial Ecology, 2017. 21(3): p. 545-558.

10. Brouwer, M.T. and E.U. Thoden van Velzen, Recyclebaarheid van verpakkingen op de Nederlandse markt. 2017: http://edepot.wur.nl/427519.

11. MCKinlay, R. and L. Morrish, Reflex Project; A summary report on the results and findings form the Reflex project. 2016: https://ceflex.eu/public_downloads/REFLEX-Summary-report-Final-reportNovember2016.pdf.

12. Kaiser, K., M. Schmid, and M. Schlummer, Recycling of polymer-based multilayer packaging: a review. Recycling, 2018. 3(1): p. 1.

13. Maris, J., et al., Mechanical recycling: Compatibilization of mixed thermoplastic wastes. Polymer Degradation and Stability, 2018. 147: p. 245-266.

14. Moreno, D.D.P. and C. Saron, Influence of compatibilizer on the properties of low-density polyethylene/polyamide 6 blends obtained by mechanical recycling of multilayer film waste. Waste Management \& Research, 2018. 36(8): p. 729-736.

15. Nechifor, M., et al., Compatibilization strategies toward new polymer materials from re-/up-cycled plastics. International Journal of Polymer Analysis and Characterization, 2018: p. 1-18.

16. Ragaert, K., L. Delva, and K. Van Geem, Mechanical and chemical recycling of solid plastic waste. Waste Management, 2017. 69: p. 24-58.

17. ten Klooster, R., et al., Zakboek verpakkingen. Zakboek Verpakkingen, 2008: p. 475-480.

18. Dixon, J., Packaging materials: 9. multilayer packaging for food and beverages. Packaging materials: 9. multilayer packaging for food and beverages., 2011.

19. Mieth, A., E. Hoekstra, and C. Simoneau, Guidance for the identification of polymers in multilayer films used in food contact materials. 2016.

20. Falla, D., NOVA Chemicals: The Changing Market - From Monolayer to Multilayer Coextrusion. FlexPackCon 2016, 2016.

21. Lamberti, M. and F. Escher, Aluminium Foil as a Food Packaging Material in Comparison with Other Materials. Food Reviews International, 2007. 23(4): p. 407-433.

22. Siracusa, V., Food Packaging Permeability Behaviour: A Report. Vol. 2012. 2012.

23. Ismail, A.F., K.C. Khulbe, and T. Matsuura, Gas separation membranes. Vol. 7. 2015: Springer.

24. Murphy, K., Are nitrogen molecules really larger than oxygen molecules. The correct answer, with respect to "permeation", is yes, 2015.

25. Ashby, M.F., H. Shercliff, and D. Cebon, Materials: engineering, science, processing and design. 2013: Butterworth-Heinemann.

26. Houlder, G., et al., Mapping flexible packaging in a Circular Economy [FIACE]. 2016.

27. Lange, J. and Y. Wyser, Recent innovations in barrier technologies for plastic packaging-a review. Packaging Technology and Science: An International Journal, 2003. 16(4): p. 149-158.

28. Williams, H., F. Wikström, and M. Löfgren, A life cycle perspective on environmental effects of customer focused packaging development. Journal of Cleaner Production, 2008. 16(7): p. 853-859.

29. Heller, M.C., S.E.M. Selke, and G.A. Keoleian, Mapping the Influence of Food Waste in Food Packaging Environmental Performance Assessments. Journal of Industrial Ecology, 2018. 
30. Spada, A., A. Conte, and M.A. Del Nobile, The influence of shelf life on food waste: A model-based approach by empirical market evidence. Journal of Cleaner Production, 2018. 172: p. 3410-3414.

31. Tromp, S.-O., et al., A systematic approach to preventing chilled-food waste at the retail outlet. International Journal of Production Economics, 2016. 182: p. 508-518.

32. Mena, C., B. Adenso-Diaz, and O. Yurt, The causes of food waste in the supplier-retailer interface: Evidences from the UK and Spain. Resources, Conservation and Recycling, 2011. 55(6): p. 648658.

33. Verghese, $K_{.}$, et al., Packaging's Role in Minimizing Food Loss and Waste Across the Supply Chain. Packaging Technology and Science, 2015. 28(7): p. 603-620.

34. Wikström, F., et al., The influence of packaging attributes on consumer behaviour in food-packaging life cycle assessment studies - A neglected topic. Journal of Cleaner Production, 2014. 73: p. 100108.

35. Williams, $H_{\text {., }}$ et al., Reasons for household food waste with special attention to packaging. Journal of Cleaner Production, 2012. 24: p. 141-148.

36. Flexible Packaging Association, Flexible Packaging Resource Recovery: A Work-in-Progress. A Summary of the Flexible Packaging Association Report: Continuing Evaluation of Resource Recovery Infrastructures and Processes. 2014.

37. Brody, A.L., High achievers in sustainable packaging. Food Technology, 2009. 63(8): p. 103-104.

38. Erickson, L.R., R.D. Behr, and R.D. Vrooman, Stand-up plastic bag and method of making same. 1989, Google Patents.

39. Izquierdo, J. and P. Feldman, 2015 Flexible Packaging Market Assessment Report. PMMI The Association for Packaging and Processing Technologies, 2015.

40. Lindh, H., A. Olsson, and H. Williams, Consumer Perceptions of Food Packaging: Contributing to or Counteracting Environmentally Sustainable Development? Packaging Technology and Science, 2016. 29(1): p. 3-23.

41. Steenis, N.D., et al., Consumer response to packaging design: The role of packaging materials and graphics in sustainability perceptions and product evaluations. Journal of Cleaner Production, 2017. 162: p. 286-298.

42. McKinlay, R. and L. Morrish, REFLEX Project: A summary report on the results and findings from the REFLEX project. 2016.

43. www.plasticseurope.org/application/files/6315/4510/9658/Plastics_the_facts_2018_AF_web.pdf. 2018.

44. Brouwer, M.T., et al., The impact of collection portfolio expansion on key performance indicators of the Dutch recycling system for Post-Consumer Plastic Packaging Waste, a comparison between 2014 and 2017. Waste Management, 2019, 100: p. 112-121.

45. Brouwer, M.T., et al., Predictive model for the Dutch post-consumer plastic packaging recycling system and implications for the circular economy. Waste Management, 2018. 71: p. 62-85.

46. Gradus, R.H.J.M., et al., A Cost-effectiveness Analysis for Incineration or Recycling of Dutch Household Plastic Waste. Ecological Economics, 2017. 135: p. 22-28.

47. https://zoek.officielebekendmakingen.nl/stb-2014-409.pdf. 2014.

48. https://eur-lex.europa.eu/legal-content/NL/TXT/PDF/?uri=CELEX:01994L006220150526\&from=EN. 2015.

49. https://www.circulairondernemen.nl/uploads/15fbc61dcb989170711acd191ed6c931.pdf. 2019.

50. Vilaplana, F. and S. Karlsson, Quality concepts for the improved use of recycled polymeric materials: A review. Macromolecular Materials and Engineering, 2008. 293(4): p. 274-297.

51. Welle, F., Twenty years of PET bottle to bottle recycling-An overview. Resources, Conservation and Recycling, 2011. 55(11): p. 865-875.

52. www.apk-ag.de/en/. 2019.

53. www.ivv.fraunhofer.de/en/forschung/verfahrensentwicklung-polymer-recycling/hochwertigeskunststoffrecycling.html. 2019.

54. www.unilever.com/news/news-and-features/Feature-article/2018/our-solution-for-recycling-plasticsachets-takes-another-step-forward.html 2018.

55. https://polystyreneloop.org/technology. 2018.

56. Reclay StewardEdge, Analysis of Flexible Film Plastics Packaging Diversion Systems. Canadian Plastics Industry Association Continuous Improvement Fund Stewardship Ontario. 2013.

57. Pedersen, T.H. and F. Conti, Improving the circular economy via hydrothermal processing of highdensity waste plastics. Waste Management, 2017. 68: p. 24-31. 
58. Anuar Sharuddin, S.D., et al., A review on pyrolysis of plastic wastes. Energy Conversion and Management, 2016. 115: p. 308-326.

59. Czajczyńska, D., et al., Potential of pyrolysis processes in the waste management sector. Thermal Science and Engineering Progress, 2017. 3: p. 171-197.

60. Al-Salem, S., et al., A review on thermal and catalytic pyrolysis of plastic solid waste (PSW). 2017. 177-198.

61. Naqvi, S.R., et al., A critical review on recycling of end-of-life carbon fibre/glass fibre reinforced composites waste using pyrolysis towards a circular economy. Resources, Conservation and Recycling, 2018. 136: p. 118-129.

62. http://news.bio-based.eu/biodegradable-plastics-and-marine-litter-expert-reactions-to-the-unepreport. 2016.

63. EN13432:2000 "Requirements for packaging recoverable through composting and biodegradationTest scheme and evaluation criteria for the final acceptance of packaging" 2000.

64. www.european-bioplastics.org/biodegradable-plastics-in-the-circular-economy-in-europe/. 2017.

65. Mazzanti, M. and R. Zoboli, Waste generation, waste disposal and policy effectiveness: Evidence on decoupling from the European Union. Resources, Conservation and Recycling, 2008. 52(10): $p$. 1221-1234.

66. https://ec.europa.eu/commission/publications/legal-documents-plastics-strategy-circulareconomy_en. 2018.

67. www.plasticseurope.org/application/files/5115/1966/5994/PlasticsEurope__Voluntary_Commitment_FINAL.PDF. 2018.

68. Velis, C., No circular economy if current systemic failures are not addressed. Waste Management \& Research, 2018. 36(9): p. 757-759.

69. Beugelsdijk, M., Visie van de Albert Heijn op het duurzaam verpakken van verse levensmiddelen, in Multivac. 2019: Woerden, Nederland.

70. www.theguardian.com/environment/2018/aug/05/walkers-plastic-crisp-packet-non-recyclable. 2018.

71. www.theguardian.com/environment/2018/oct/05/walkers-answers-critics-with-launch-of-uk-crisppacket-recycling-plan. 2018.

72. www.terracycle.co.uk/en-GB/zero_waste_boxes/candy-and-snack-wrappers. 2018.

73. http://ec.europa.eu/environment/waste/framework/. 2008.

74. https://packagingeurope.com/parkside-launches-fully-recyclable-flexible-packaging-laminate/. 2018.

75. www.mondigroup.com/en/newsroom/media-centre/press-releases/2018/mondi-s-fully-recyclablepackaging-material-barrierpack-recyclable-drives-circular-economy-forward/. 2018.

76. www.amcor.com/product-listing/amlite-ultra. 2019.

77. www.nippon-gohsei.com/gohsenol. 2019.

78. www.biobasedworldnews.com/uks-biggest-crisp-brand-walkers-launches-uk-recycling-scheme-forcrisp-packets. 2018.

79. Moreno, D.D.P. and C. Saron, Influence of compatibilizer on the properties of low-density polyethylene/polyamide 6 blends obtained by mechanical recycling of multilayer film waste. Waste Management \& Research, 2018. 00(0): p. 1-8.

80. Wang, Y., et al., New Approach to Optimize Mechanical Properties of the Immiscible Polypropylene/Poly (Ethylene Terephthalate) Blend: Effect of Shish-Kebab and Core-Shell Structure. Polymers, 2018. 10(10): p. 1094.

81. www.uantwerpen.be/en/projects/design-from-recycling/. 2018.

82. https://recyclass.eu/recyclability-evaluation-protocols/ 



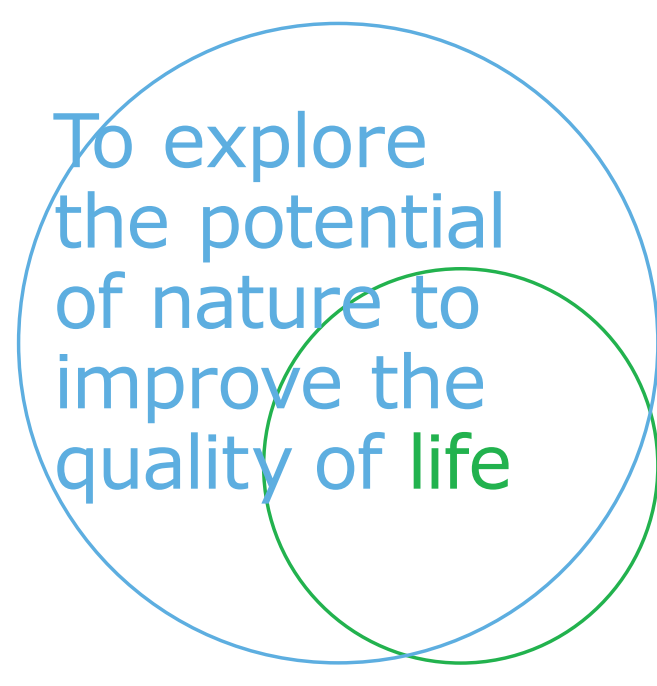

Wageningen Food \& Biobased Research Bornse Weilanden 9

6708 WG Wageningen

The Netherlands

www.wur.eu/wfbr

Einfo.wfbr@wur.nl

Report 2037

ISBN 978-94-6395-370-2

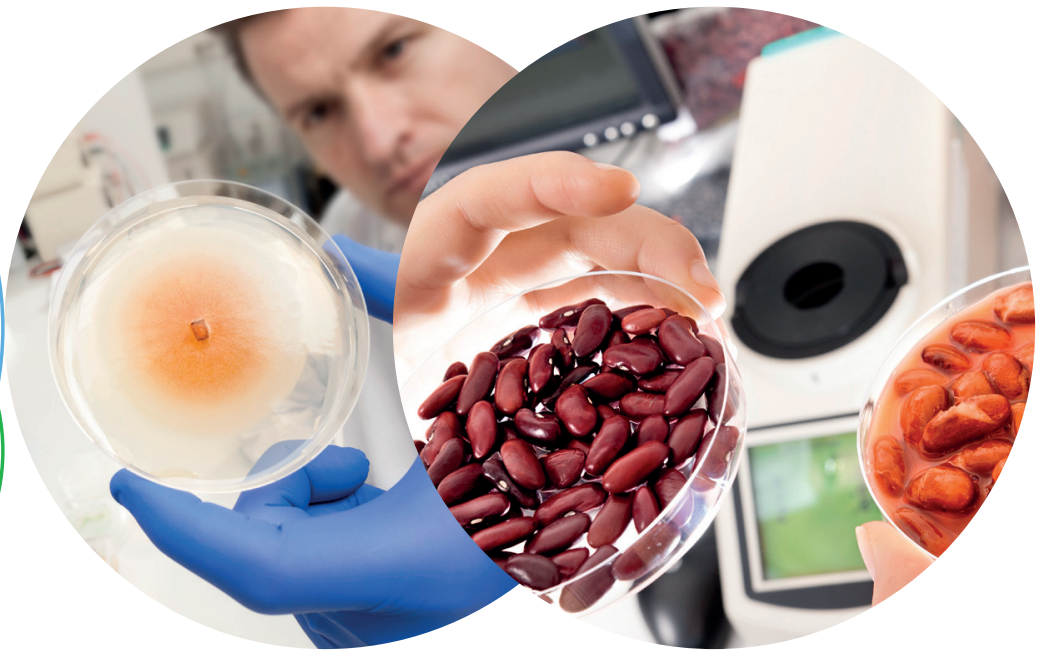

The mission of Wageningen University and Research is "To explore the potential of nature to improve the quality of life". Under the banner Wageningen University \& Research, Wageningen University and the specialised research institutes of the Wageningen Research Foundation have joined forces in contributing to finding solutions to important questions in the domain of healthy food and living environment. With its roughly 30 branches, 5,000 employees and 12,000 students, Wageningen University \& Research is one of the leading organisations in its domain. The unique Wageningen approach lies in its integrated approach to issues and the collaboration between different disciplines. 